Chinese Journal of Organic Chemistry

\title{
黄酮苷的合成研究进展
}

\author{
徐焕基 ${ }^{a}$ 李哲明 ${ }^{a}$ 吴云秋 ${ }^{a}$ 罗 迪 ${ }^{a}$ \\ 邱 莉 ${ }^{a}$ 谢集照 $*, a, b$ 李雪华 $*, a$ \\ ( ${ }^{a}$ 广西医科大学药学院 南宁 530021) \\ ( $b$ 广西大学化学化工学院 南宁 530004)
}

\begin{abstract}
摘要 黄酮苷广泛存在于自然界植物, 具有广泛的药理活性和潜在的药用价值, 其合成方法值得研究, 对 2014 年至 2018 年黄酮苷的合成进行综述. 黄酮苷的合成主要包括化学合成和生物合成两大类, 而化学合成又分为全合成和半合 成, 其中全合成主要有 $\beta$-丙二酮酸化关环法(Baker-Venkataraman, BK-VK 法)和查尔酮氧化关环法(Algar-FlynnOyamada, AFO 法)两种经典方法; 半合成是以芦丁、葪皮素、山菜酚、柚皮素等天然黄酮为原料. 黄酮氧苷的化学合成 目前常用的方法有三种: Koening-Knorr 法、相转移催化法、糖基三氯乙酰亚胺酯法. 黄酮碳苷的糖苷链的连接主要是 通过 $\mathrm{O} \rightarrow \mathrm{C}$ 重排法. 酶催化生物合成法目前常用的酶是糖基转移酶和糖苷合酶这两种酶.
\end{abstract}

关键词 黄酮苷; 合成; 苷元; 糖苷缩合; 综述

\section{Advances on Synthesis of Flavonoid Glycosides}

\author{
Xu, Huanji ${ }^{a} \quad$ Li, Zheming $^{a} \quad \mathrm{Wu}$, Yunqiu $^{a} \quad$ Luo, $^{a}{ }^{a}$ \\ Qiu, $\mathrm{Li}^{a} \quad \mathrm{Xie}, \mathrm{Jizhao}^{*, a, b} \mathrm{Li}, \mathrm{Xuehua*,a}$ \\ ( ${ }^{a}$ School of Pharmacy, Guangxi Medical University, Nanning 530021) \\ ( ${ }^{b}$ School of Chemistry and Chemical Engineering, Guangxi University, Nanning 530004)
}

\begin{abstract}
Flavonoid glycoside is commonly found in natural plants, possesses diverse bioactivities and potential medicinal values, and its synthesis methods are worthy to be studied. The synthesis of flavonoid glycosides covering the literatures from 2014 to 2018 is reviewed. The flavonoid glycoside synthesis includes two major methods of chemosynthesis and biosynthesis. Chemosynthesis includes total synthesis and semi-synthesis. The total synthesis has two classical methods of the BakerVenkataraman (BK-VK) reaction and the Algar-Flynn-Oyamada (AFO) reaction. The semi-synthesis is usually starting from natural flavonoid, such as rutin, quercetin, kaempferol, naringenin and so on. Moreover, the chemosynthesis of flavonoid $O$-glucoside has three prime methods, Koening-Knorr method, phase transfer catalysis method, and glycosyl trichloroacetimidate method. As for the chemosynthesis of flavonoid $C$-glycoside, its glycosidic linkage is mainly completed via the $\mathrm{O} \rightarrow \mathrm{C}$ rearrangement reaction. Currently, the glycosyltransferase and glycosynthase are usually employed in the enzyme-catalyzed biosynthesis of flavonoid glycosides.
\end{abstract}

Keywords flavonoid glycosides; synthesis; flavonoid aglycones; condensation of glycosides; review

黄酮苷(flavonid glycoside)是黄酮苷元与糖基通过 苷键连接形成的化合物. 其中, 通过碳一氧键连接的称 为黄酮氧苷, 碳一碳键连接的称为黄酮碳苷. 黄酮苷类 广泛存在于自然界植物, 具有抗炎 ${ }^{[1,2]}$ 、抗氧化 ${ }^{[3 \sim 5]}$ 、抗 肿瘤 ${ }^{[6,7]}$ 、抗菌 ${ }^{[8,9]}$ 、降血糖 ${ }^{[10,11]}$ 等药理活性. 研究表明, 糖链是重要的生物分子和信息载体, 参与细胞生物几乎 所有的生命过程, 特别是在细胞分化、发育、免疫、老
化、癌变、信息传递等生命基础活动和重大疾病过程中 起着特异性的识别、介导与调控作用 ${ }^{[12 \sim 14]}$. 除此之外, 糖基化可改变药物的生物活性, 增加水溶性, 降低毒副 作用, 提高特异靶向性等特点, 具有广阔的发展前 景 ${ }^{[15 \sim 17]}$. 目前黄酮苷主要是从植物中提取分离, 但是许 多具有良好活性的黄酮苷在植物中的含量较低 ${ }^{[18,19]}$. 如 nervilifordins $F$ 和 $G$ 是自然分布于两广少数民族地区的

* Corresponding authors. E-mail: xiejizhao@gxmu.edu.cn; onlythankforyou@163.com

Received November 1, 2018; revised January 23, 2019; published online February 19, 2019.

Project supported by the National Natural Science Foundation of China (No. 21662005).

国家自然科学基金(No. 21662005)资助项目. 
特产名贵药材青天葵的黄酮氧苷，具有良好的抗炎活 性, 但药材资源稀缺, 且从青天葵的干燥地上部分提取 的产率仅为 $1.2 \%$ 和 $0.6 \%{ }^{[20]}$, 极大限制了对其研究及潜 在药用价值的开发利用. 正因为黄酮苷具有这些独特的 性质, 其黄酮苷的合成研究日益受到重视. 2011 年 Kondo 等 ${ }^{[21]}$ 综述报道了 2000 年至 2010 年关于黄酮及黄 酮苷的合成; 2013 年 Wang 等 ${ }^{[22]}$ 对天然黄酮及黄酮苷的 首次合成进行了综述; 2014 年梅青刚等 ${ }^{[23]}$ 对黄酮醇的合 成进行了概述; 2014 年 $Y u$ 等 ${ }^{[24]}$ 对黄酮氧苷的合成作了 综合报道; 2017 年 Iranshahi 等 ${ }^{[25]}$ 对一锅法合成黄酮作了 综合概述; 2018 年 Suzuki 等 ${ }^{[26]}$ 对芳香糖苷的合成作了一 个全面综述, 包括黄酮碳苷的合成. 国内外对黄酮苷的 合成研究虽然较多, 对于那些常用的糖苷化反应的合成 产率仍较低, 特别是区域选择性糖苷化, 尤其是涉及到 多个糖苷合成时, 产率更低. 随着生物技术的发展, 酶 催化生物合成的黄酮苷也越来越广泛，2014 年 Xiao 等 ${ }^{[27]}$ 和 2016 年 Hofer ${ }^{[28]}$ 分别综述报道了酶催化和微生 物代谢工程合成黄酮苷. 2014 年来关于黄酮的合成只针 对某一面的综述，因此本文对近几年黄酮苷的合成研究 作一较系统全面的综述.

黄酮苷的合成主要包括化学合成和酶催化生物两 种类型，化学合成法又分为全合成和半合成.

\section{1 黄酮苷元的合成}

在黄酮苷的化学合成中, 苷元与糖链的连接是最关 键的步骤. 全合成反应需要的步骤相对比较冗长, 但是 可以根据目标分子的结构特点而灵活设计合成路线，可 以构建自然界中不存在的及大量合成自然界中含量极 低的苷元.

\section{1 黄酮苷元的全合成}

目前黄酮苷元的全合成有经典的两种方法, 即 $\beta$-丙 二酮酸化关环法(Baker-Venkataraman, BK-VK 法)和查 尔酮氧化关环法(Algar-Flynn-Oyamada, AFO 法).

\subsubsection{Baker-Venkataraman 法}

Baker-Venkataraman (BK-VK) 反应是合成黄酮的最 常用的方法，也是最简便的方法，该反应经过了酯化和 分子内重排两步反应，反应条件较为温和.

由于传统 $\mathrm{BK}-\mathrm{VK}$ 法通常需要剧烈的反应条件, 并 且产率较低. 近年来, 人们对所用碱催化剂、相转移催 化法以及硅烷基羟基保护等方面进行不断改良，同时设 法使酯化和克莱森重排两步反应同步进行.

文献报道 ${ }^{[29]}$ ，在大量合成 5-甲氧基黄酮时，传统 BK-VK 法存在产率低和产物分难离的问题. 因此，使用 相转移催化剂使酯化和重排两步反应连续同步进行，从 而避免了反应物苯甲酰氯与克莱森重排目标产物分离 困难的情况，且提高了产率. 传统 BK-VK 法由于剧烈 的反应条件和长时间反应使敏感性的甲氧基水解，导致 传统 BK-VK 法合成 5-甲氧基黄酮产率低. 然而, 在碱 性较弱 $\mathrm{K}_{2} \mathrm{CO}_{3}$ 的温和条件下使用相转移催化剂叔丁基 醇钾，对 BK-VK 法这样的亲核反应是有利的，从而使 得回收率得到大大的提高 ${ }^{[30]}$.

在对影响 BK-VK 反应酯化和重排二步反应的因素 如溶剂、碱催化剂和闭环试剂等的研究中, 发现以丙酮 为溶剂、 $\mathrm{K}_{2} \mathrm{CO}_{3}$ 为碱、 $\mathrm{HOAc}-\mathrm{NaOAc}$ 闭环试剂反应体系 最有效，且具有反应条件温和、操作简便、收率提高、 溶剂成本降低、易于回收、反应时间缩短等优点 ${ }^{[31]}$.

在合成金合欢素 7-O- $\beta$ - $D$-吡喃半乳糖苷(5)的研究 中，直接以廉价易得的 2,4,6-三羟基苯乙酮(1)和对甲氧 基苯甲酰氯(2)为原料, 在 $\mathrm{K}_{2} \mathrm{CO}_{3}$ 催化下, 通过 $\mathrm{BK}-\mathrm{VK}$ 反应一步合成金合欢素(3). 考察了在不同溶剂、不同路 易斯酸催化剂条件下，不同构型的乙酰基保护的氟代半 乳糖进行糖苷化反应对糖苷化产物构型影响，结果发 现，各种溶剂、路易斯酸、糖基供体得到的主要是 $\beta$ 构 型的糖苷化产物, 其中以二氯甲烷为溶剂, $\mathrm{BF}_{3} \cdot \mathrm{OEt}_{2}$ 为 催化剂, 糖基供体为 $\beta$ 构型时, 糖苷产物 $\alpha 、 \beta$ 构型的比 例为 $3: 97$, 总收率高达 46\% (Scheme 1) ${ }^{[32]}$. 该反应步
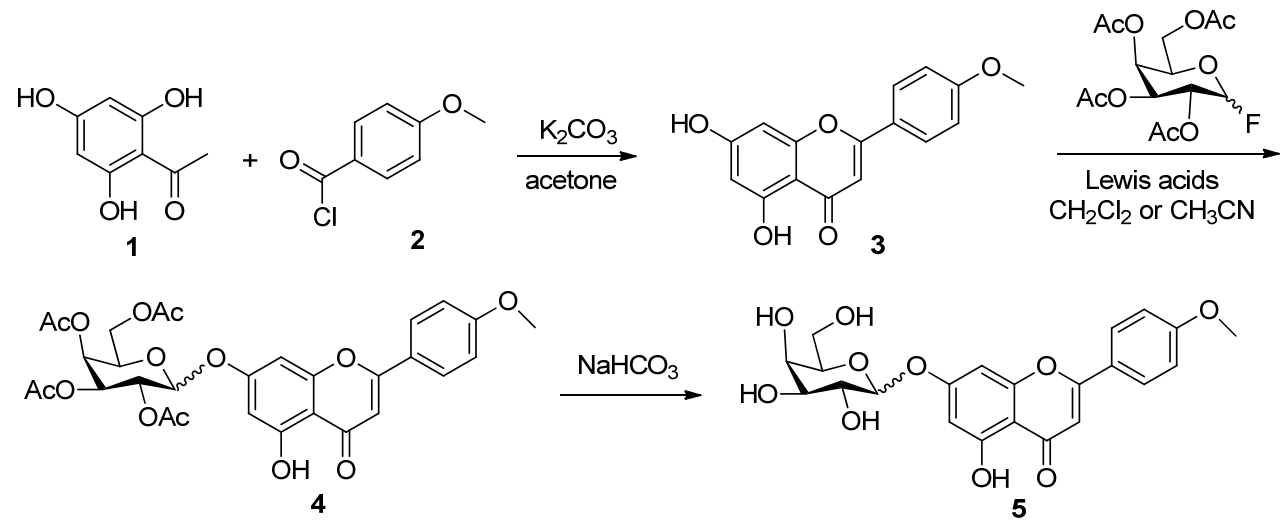

图式 1 金合欢素 7-O- $\beta-D$-吡喃半乳糖苷的全合成路线

Scheme 1 Total synthetic route of acacetin-7-O- $\beta$ - $D$-galactopyranoside 
骤较短, 同时糖苷化产物主要为 $\beta$ 构型, 与绝大多数天 然糖苷类产物为 $\beta$ 构型相一致, 对于天然糖苷化合物的 合成具有重要参考意义.

2015 年首次报道了通过全合成法获得具有良好抗 病毒活性的天然产物鱼腥草素 B (11 $)^{[33]}$. 首先以苄基保 护的白杨素通过逆醛醇反应降解得到苯乙酮衍生物, 接 着通过 Rubottom 氧化反应得到着基化产物, 然后在 $\mathrm{BF}_{3} \cdot \mathrm{OEt}_{2}$ 催化下，与乙酰基保护的溴代半乳糖进行糖基 化反应得到半乳糖基化的羟基苯乙酮(7)关键结构单元; 以 3,4-二羟基苯甲醛与炔烃合成苯并呋喃结构单元, 再 与苯并三唑衍生成活性的芳基酯(6). 最后, 在 $\mathrm{NaH}$ 存在 下, 半乳糖基化的羟基苯乙酮与活性的芳基酯(6)进行 酯化反应得到糖基芳基酯(8), 然后在 $\mathrm{K}_{2} \mathrm{CO}_{3}$ 催化剂、四 丁基溴化铵( $\mathrm{TBAB}$ )相转移催化剂催化下, 通过 BK- VK 重排、环化脱水构建黄酮碳骨架, 最后脱芐基和乙酰基 得到鱼腥草素 B (11), 总收率为 $11.0 \%$ (Scheme 2). 在上 述反应过程中, 首先通过合成目标化合物结构片段, 最 后通过 BK-VK 重排、环化脱水关键步骤构建黄酮碳骨 架, 这在合成苯并含 $\mathrm{O} 、 \mathrm{~N}$ 等杂环黄酮时有借鉴意义.

\subsubsection{Algar-Flynn-Oyamada (AFO)法}

查尔酮是合成黄酩的关键中间体. 查尔酮氧化关环 法又称 Algar-Flynn-Oyamada (AFO) 法, Algar-Flynn-
Oyamada 法最初由爱尔兰的 Algar、Flynn ${ }^{[34]}$ 和日本的 Oyamada $^{[35,36]}$ 于 1934 年同时发现, 后来广泛应用于黄 酮醇的合成 ${ }^{[37 \sim 39]}$.

多甲氧基黄酮具有显著抗癌、抗炎等活性，但其水 溶性差, 对生物受体的亲和能力不强, 而进行糖基化后 可大大改善上述缺点, 近年来对其化学全合成及其糖苷 化的研究日益受到重视 ${ }^{[40]}$. 文献报道, 以相应甲氧基的 苯乙酮和苯甲醛衍生物为原料, 通过 $\mathrm{AFO}$ 反应合成了 一系列多氧甲基黄酮醇, 并以其中的 3',4',7-三甲氧基黄 酮醇为苷元与不同的乙酰基保护的溴代糖进行糖苷缩 合反应, 得到一系列以常见的单糖为糖基的 $3^{\prime}, 4^{\prime}, 7$-三甲 氧基黄酮苷 ${ }^{[41]}$.

继 2015 年报道全合成鱼腥草素 B 之后, 2018 年报 道了全合成了鱼腥草素的重要成员之一鱼腥草素 A $(\mathbf{2 0})^{[42]}$, 类似上例合成鱼腥草素 $\mathrm{B}$ 一样, 首先合成目标 化合物结构片段, 再构建黄酮骨架. 在本例中, 首先将 3,4-二羟基苯甲醛合成苯并呋喃醛(13)结构单元, 然后 在 $\mathrm{NaOH}$ 碱性条件下, 苯并呋喃醛(13)与廉价易得的芳 基酮(12)羟醛缩合反应生成查尔酮中间体(14), 然后 $\mathrm{I}_{2}$ 氧化关环、过氧丙酮(DMDO)氧化羟基化、 $\mathrm{HOAc} / \mathrm{H}_{2} \mathrm{O}$ 选择性去 5-芐基后得到黄酮醇(18), 再在 $\mathrm{K}_{2} \mathrm{CO}_{3}$ 催化下, 与乙酰基保护的溴代糖糖基供体进行缩合反应，最后去

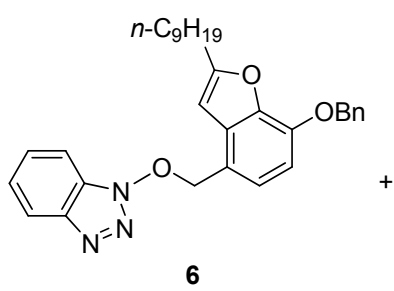

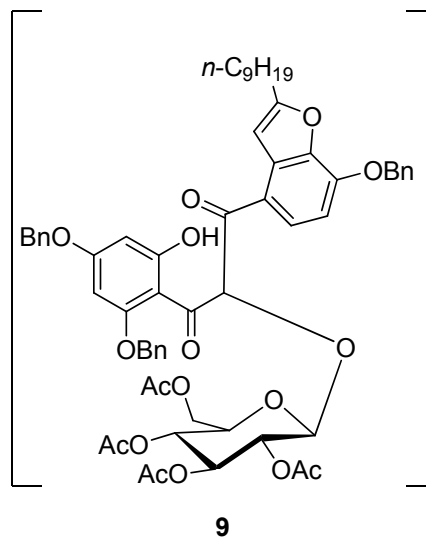

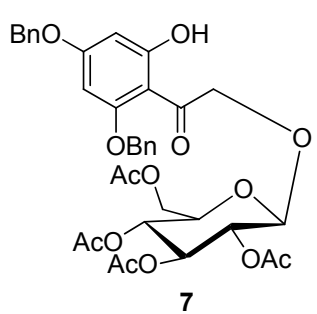

$\mathrm{NaH} / \mathrm{THF}$

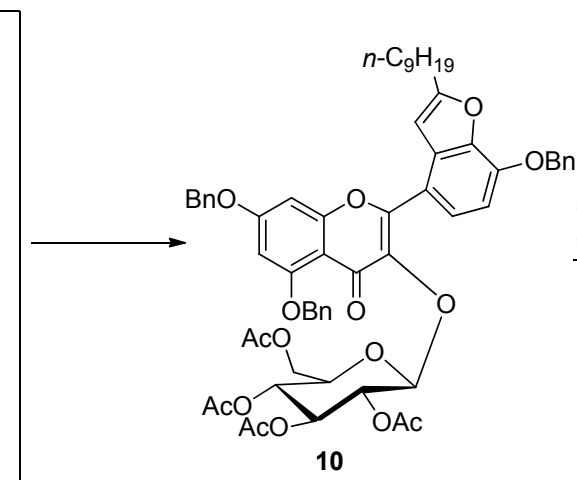

图式 2 鱼腥草素 B 的全合成路线

Scheme 2 Total synthetic route of houttuynoid B
(1) $\mathrm{Pd} / \mathrm{C} / \mathrm{H}_{2} / \mathrm{THF}$, EtOH (2) $\mathrm{NaOMe} / \mathrm{MeOH}$

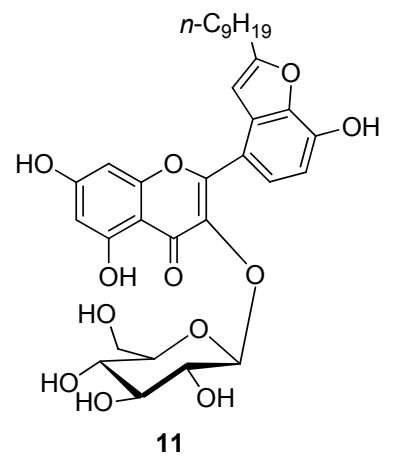


乙酰基、去苠基得到目标产物鱼腥草素 A (20), 总收率 为 $8.0 \%$ (Scheme 3$)$. 值得注意的是, 本例与上例合成鱼 腥草素 $\mathrm{B}$ 一样, 反应步骤繁多, 总收率不高. 不同的是 上例合成鱼腥草素 $\mathrm{B}$ 是首先合成糖基化的羟基苯乙酮 关键结构单元，再通过 BK-VK 反应构建黄酮骨架，而 本例是首先通过 AFO 反应合成黄酮醇, 最后再进行糖 基化.

BK-VK 反应和 AFO 反应均具有原料廉价易得, 溶 剂成本降低，反应步骤易于操作等优点. 但是合成黄酮 醇时, 需要经过黄酮中间体, 反应步骤多, 产率一般也 不高. 查尔酮是合成各类黄酮的重要中间体, 在不同的 氧化条件下, 可得到不同类型的黄酮化合物. AFO 反应 是目前人们普遍应用于合成黄酮醇的一种方法, 但该反 应受底物取代基和反应温度的影响较大，副产物较多， 分离纯化较困难. 人们可根据目标化合物情况, 灵活选 择这两种方法.

\subsection{1 以天然黄酮苷为原料}

以黄酮苷为原料，一般经过乙酰化、苯甲酰化或茮 基化、酸水解等反应，得到保护基保护的黄酮苷元，再
与糖基供体进行糖苷化反应. 如以芦丁(21)为原料，经 过苄基化、酸水解得到苄基保护的檞皮素，再与乙酰基 保护的溴代糖进行糖苷化反应，然后经过去乙酰基和去 苄基等步骤获得系列檞皮素 3-糖苷、3,4'- $O$-二糖苷和 $3,7-O$-二糖苷 ${ }^{[43]}$. 由于共轭效应而使得槲皮素的 $7 、 4^{\prime}$ 与 3 位羟基活性更高，因此，在合成葪皮素 7- $O$-糖苷时, 3 位和 4 '位羟基一般需选择性保护起来. 文献报道, 芦 丁(21)经过选择性苄基化、酸催化水解、选择性 3-羟基 烷基化、氢化去苄基后，以二苯基甲叉选择性保护 $3^{\prime}, 4^{\prime}$ 位羟基，再选择性 7 位羟基糖基化，得到葪皮素 7-O-糖 基化的关键中间体(26a 26d)，再经过去二苯基甲叉保 护基、苯乙酰基等步骤合成了一系列槲皮素 7-O- $\beta-D-$ 吡喃葡萄糖苷 $(\mathbf{2 7} \mathbf{a} \sim 27 \mathbf{d})^{[44,45]}$ (Scheme 4).

柚皮苷和橙皮苷是天然二氢黄酮苷，广泛分布于柑 桔、柚子等芸香科属植物中. 文献报道，柚皮苷和橙皮 苷经过糖苷水解、碘/吡啶脱氢、甲基化或苄基保护、催 化氢化脱茮基、糖基化等反应步骤，得到了一系列多甲 氧基黄酮苷 ${ }^{[40,46]}$.

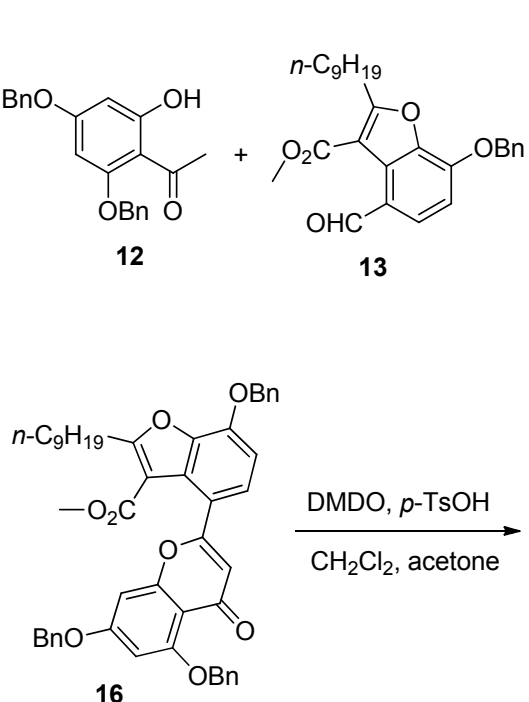

16
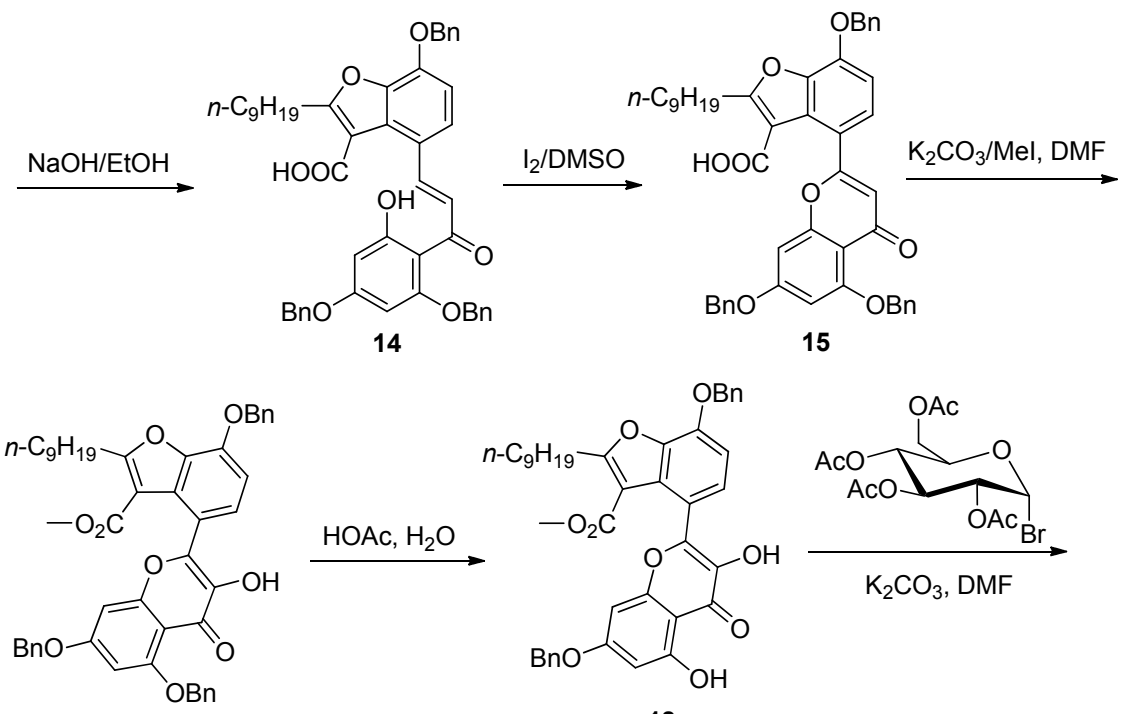

17

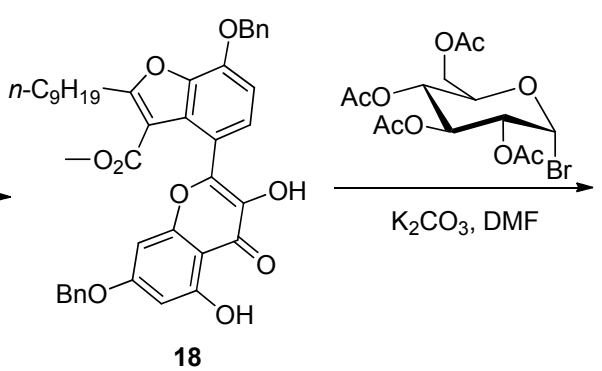

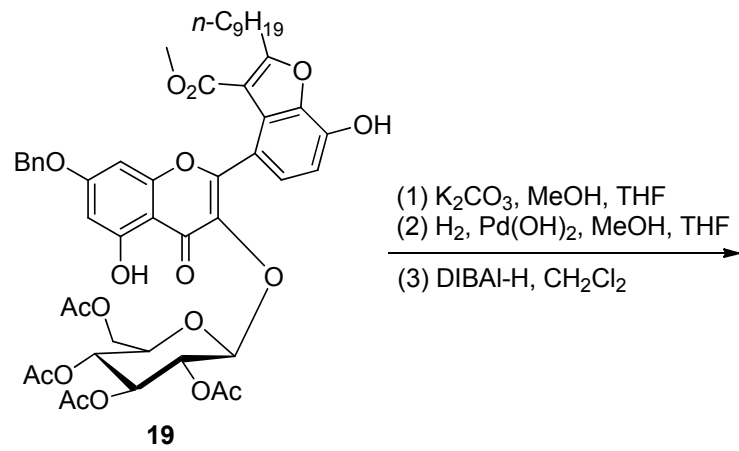

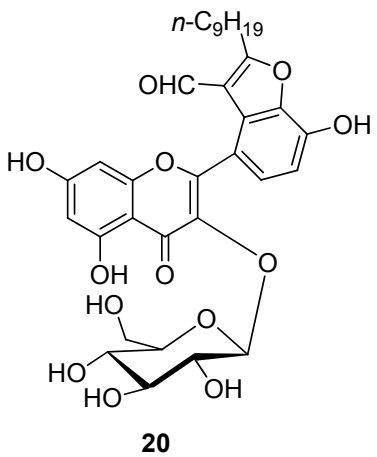

图式 3 鱼腥草素 $\mathrm{A}$ 的合成路线

Scheme 3 Total synthetic route of houttuynoid A 
<smiles></smiles>

21<smiles>[R]c1c(-c2ccc(O)c(O)c2)oc2cc(O)cc(O)c2c1=O</smiles>

24

$\mathrm{OH}$

(1) $\mathrm{BnBr}, \mathrm{K}_{2} \mathrm{CO}_{3}, \mathrm{DMF}$

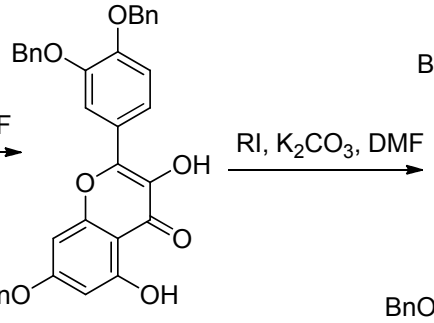

22<smiles>[R]Oc1c(-c2ccc(OCc3ccccc3)c(OCc3ccccc3)c2)oc2cc(O)cc(O)c2c1=O</smiles>

23

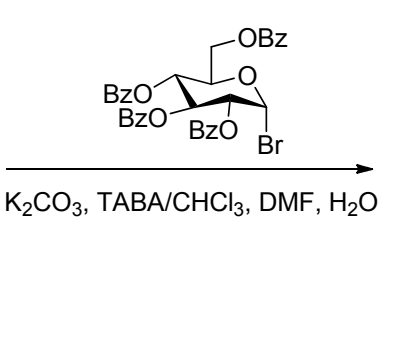

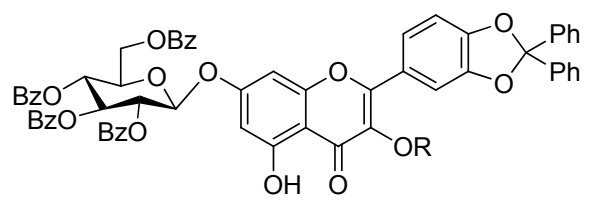

26

25

(1) $10 \% \mathrm{Pd} / \mathrm{C}, \mathrm{H}_{2}, \mathrm{MeOH}, \mathrm{THF}, \mathrm{H}_{2} \mathrm{O}$

(2) $\mathrm{NaOMe} / \mathrm{MeOH}, \mathrm{CH}_{2} \mathrm{Cl}_{2}$<smiles>[R]Oc1c(-c2ccc(O)c(O)c2)oc2cc(OC(O)C(O)C(O)CO)cc(O)c2c1=O</smiles>

$23 \sim 27 \mathrm{a} R=\mathrm{Me}$
$23 \sim 27 \mathrm{~b} R=\mathrm{Et}$
$23 \sim 27 \mathrm{c} \quad \mathrm{R}=n-\mathrm{Pr}$

$23 \sim 27 \mathrm{~d} R=$

图式 4 䚞皮素 7-O-糖苷半合成路线

Scheme 4 Semi-synthetic route of quercetin 7-O-glycoside

\subsection{2 以天然黄酮醇为原料}

以天然的黄酮醇为原料, 利用苯环上酚羟基位置不 同而导致反应活性大小不同的性质, 进行选择性取代得 到多种取代的黄酮苷. 其中黄酮醇以槲皮素、山奈酚最 为常见. Park 等 ${ }^{[47]}$ 报道在 $\mathrm{K}_{2} \mathrm{CO}_{3} / 1$,4-二氧六环体系中, 桷皮素(28)直接与乙酰基保护的溴代糖进行糖苷化反 应, 然后在 $\mathrm{NH}_{3} / \mathrm{MeOH}$ 碱性条件下去乙酰基得到葪皮 素 3-O- $\beta-D$-葡糖苷(30), 收率为 60\% (Scheme 5). Yang 等 ${ }^{[48,49]}$ 以山菜酚为原料, 合成了系列山荎酚 3- $O$-糖苷和 山菜酚 3,7-二糖苷化合物. 山奈酚衍生物是淫羊蒦苷具

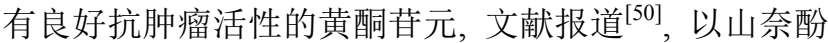
为原料, 经过 11 个线性步骤半合成了淫羊蕉苷, 总收率 为 7\%. 芹菜素 7-O- $\beta-D$-吡喃葡萄糖- $4{ }^{\prime}-O-\alpha-L$-吡喃糖苷 具有抑制乙型肝炎病毒复制、抗中风等活性的天然产物, 有研究报道直接以柚皮素为原料与苯甲酰基保护的溴 代糖糖苷化, 2,3 位氧化脱氢, 再与苯甲酰基保护的溴代 糖糖苷化反应，碱水解苯甲酰基保护基四步反应，合成 了目标产物, 并经过同样的方法获得芹菜素 7,4'-二-O$\beta$ - $D$-吡喃葡萄糖苷，总收率为 $45 \%{ }^{[51]}$. 该法具有反应步 骤较短、友好、廉价等优点.<smiles>O=c1c(O)c(-c2ccc(O)c(O)c2)oc2cc(O)cc(O)c12</smiles>

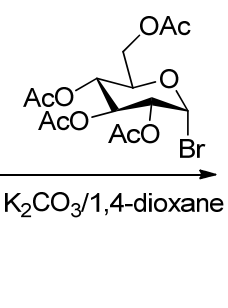

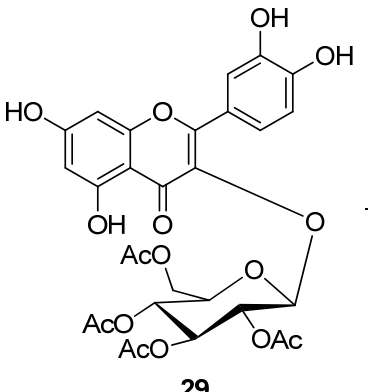

29<smiles>O=C1C(OC2OC3OC2C(O)C(O)C(O)C3O)=C2C(=O)c3c(O)cc(O)cc3OC(c3ccc(O)c(O)c3)=C12</smiles>

30

图式 5 䚞皮素 7-O-糖苷半合成路线

Scheme 5 Semi-synthetic route of quercetin 7-O-glycoside 


\section{2 黄酮苷的合成}

\section{1 黄酮氧苷的合成}

糖苷链的合成一般是在糖基供体和糖基受体在催 化剂作用下进行的. 黄酮氧苷合成的方法目前已有二十 多种，目前常用的有三种: Koening-Knorr 法、糖基三氯 乙酰亚胺酯法、相转移催化法, 而金( $\mathrm{Au}(\mathrm{I})$ ) 催化的糖邻 炔基苯甲酸酯法可高效合成黄酮 5- $O$ 糖苷. 目前最常用 的糖基给体有糖基卤化物、糖基三氯乙酰亚胺酯、邻炔 基苯甲酸糖基酯和硫苷等.

\subsubsection{Koenig-Knorr 法}

经典的 Koenig-Knorr 法始于 1901 年 ${ }^{[52]}$, 经过百年 来不断发展已成为一个常用的合成糖苷和寡糖的方法, 在早期合成黄酮苷时被广泛应用 ${ }^{[53 \sim 55]}$. 常以本乙酰基 和乙酰基保护的卤代糖作糖基供体，苯、甲苯、吡啶以 及喹啉等作溶剂, 重金属盐(录盐或银盐)作催化剂, 无 水硫酸钙、 $4 \AA$ 分子篮作除水剂. Koenig-Knorr 法在糖苷 合成中应用比较早, 条件简便并且比较成熟, 但是由于 产率低、区域选择性差, 糖基给体不稳定, 无水条件苛 刻, 并且使用的催化剂录盐或银盐昂贵且有毒, 对环境 不友好, 后处理步骤相对比较烦琐等缺点, 近年来该方 法使用逐渐减少.

黄芩苷是传统中草药黄芩的主要成分之一, 具有抗 氧化、抗病毒、抗 HIV、保肝等生物活性. Mezey-Vandor 等 ${ }^{[56]}$ 以黄芩素为苷元, 直接以溴代的葡萄醛酸为糖基 供体进行糖基化反应, 获得所需的目标产物, 产率较低 $(40 \%)$. 在碳水化合物合成反应中, 其中具有挑战性的 主要问题之一是糖苷化反应产率较低, 而葡萄糖醛酸糖 基供体比一般的糖基供体的反应活性更低, 导致糖苷化 反应产率进一步降低. 并且, 在 Koenig-Knorr 反应条件 下, 葡萄醛酸甲酯糖基供体不稳定, 进行消除反应产生 2-酰氧基乙二醇副产物 ${ }^{[57]}$. 因此, $\mathrm{Li}$ 等 ${ }^{[5,59]}$ 对糖基供体 进行改进, 首先以硅烷基、苯乙酰基保护的溴代葡萄糖 为糖基供体进行糖基化反应, 获得所需的糖基化产物 (糖苷化产率 92\%), 然后再选择性去 6 位保护基, 通过 Widlanski 氧化(TEMPO/BAIB) 形成羧酸获得葡糖糖醛 酸糖苷化的目标产物, 葡萄醛酸化产率 $59 \%$. 在反应过 程中, 首先以 3,4,5-三甲氧基苯酚(31) 和肉桂酰氯(32)为 原料, 经过酰化、查尔酮氧化闭环、去甲基等反应得到 黄芩素(39), 接着, 再经过区域选择性 5,6,7-三差基乙酰 化、7-乙酰基苄基化、去 7-芐基等步骤得到 5,6-二乙酰 基黄芩素(38). 然而, 与 $N$-苯基三氟乙酰亚胺糖基酯和 金催化的邻炔基苯甲酸糖基酯为糖基供体进行糖苷化 反应, 结果却得不到糖基化产物, 因此, 通过经典的 Koenigs-Knorr 法, 以喹啉作溶剂、 $\mathrm{Ag}_{2} \mathrm{O}$ 作催化剂、 $4 \AA$
分子篮作除水剂，与溴代葡萄糖糖进行糖苗化反应获得 糖苷产物, 最后经过去保护基反应得到黄芩苷(42), 总 产率为 27\% (Scheme 6). 在反应中, 通过使用 KoenigKnorr 法成功地构建关键的糖苷键，同时也通过该法使 黄芩素苷元与不同的糖基供体进行糖苷化反应, 得到了 四种黄芩苷衍生物, 糖苷化产率达 $85 \%$ ～94\%. 在上述 反应中，体现了糖苷化反应的局限性和上述合成路线 Koenig-Knorr 法的一般适用性. 因此, 这种传统的 Koenig-Knorr 法在其他糖苷化不适合的条件下仍然具有 适用性.

\subsection{2 相转移催化法}

相转移催化法是在经典 Koenig-Knorr 法上发展起 来，常以邻位酰基等保护的澳代糖为糖基给体，是合成 黄酮醇 3-糖苷的首选方法 ${ }^{[26]}$. 该法具有操作简便, 反应 速度快, 反应条件温和, 后处理简单和立体选择性强, 提高了产率，避免了使用价格昂贵的重金属盐，以及银 盐法中卤代糖基不稳定等优点. 其中，四丁基溴化铵 (TBAB) 是目前最常用的相转移催化剂.

Demetzos 等 ${ }^{[60]}$ 在 $\mathrm{CHCl}_{3} / \mathrm{KOH}$ 体系中, 使用相转移 催化剂三乙硫醇胺(TMEA)催化乙酰基保护的溴代糖与 7,4-二- $O$-芐基槲皮素反应，得到系列檞皮素 3- $O$-糖苷， 产率为 $10 \% \sim 60 \%$. 进一步地, 在无水丙酥/水碳酸钾体 系中, 以 $\mathrm{TBAB}$ 为相转移催化剂催化乙酰基溴代葡萄糖 与 5,6,7,8,3,4'-六甲氧基黄酮醇进行糖苷化反应, 然后在 $30 \%$ 氨水碱性条件下脱乙酰化得到 $5,6,7,8,3^{\prime}, 4^{\prime}$ - 六甲氧 基黄酮-3- $O-\beta$-葡萄糖苷, 产率为 $85.0 \%{ }^{[61]}$. 在相转移催 化法的反应过程中, 使用碱性相对 $\mathrm{KOH}$ 更弱的 $\mathrm{K}_{2} \mathrm{CO}_{3}$, 降低碱的浓度的同时也减少了溴代糖水解副反应的发 生，提高了产率.

在合成檞皮素 3- $O$-(2-氨基-2-脱氧)- $D$-葡萄糖苷研 究中, 首先以芦丁 (21) 为原料, 经过选择性芐基化、酸水 解反应得到 7,4'-二芐基葪皮素(44), 并以此为苷元进行 对传统的 Koening-Knorr 法、相转移催化法、糖基三氯 乙酰亚胺酯三种糖苷缩合反应研究, 结果发现只有在 $\mathrm{CHCl}_{3} / \mathrm{K}_{2} \mathrm{CO}_{3}$ 体系, 以 $\mathrm{TBAB}$ 为相转移催化剂, 苷元才 能与乙酰基保护的卤代 2-氨基-2-脱氧- $D$-葡萄糖糖基供 体发生糖苦化反应获得目标产物. 其中, 以乙酰基保护 的氯代 2-乙酰氨基-2-脱氧- $D$-葡萄糖(47)为糖基供体反 应得到槲皮素 3-O-1,2-反式糖苷(49) (Scheme 7). 然而, 以乙酰基保护的澳代 $N$-邻苯二甲酰亚胺基-2-脱氧- $D$ 葡萄糖(51)为糖基供体得到槲皮素 3-O-1,2-顺式糖苷 $(\mathbf{5 2})^{[62]}$ (Scheme 8). 此外, 通过类似的反应合成了䚞皮 素 3-O、3' $-O$ 和 4' $-O-N$-乙酰氨基葡萄糖苷 3 种黄酮苷 ${ }^{[63]}$. 在碳水化合物化学中, 由于糖基供体的 2- $O$-酰基不具有 邻基参与作用，从而造成 1,2-顺式糖苷的立体选择性 
<smiles>COc1cc(O)cc(OC)c1OC</smiles>

31<smiles>O=C(Cl)/C=C/c1ccccc1</smiles>

32<smiles>COc1cc(O)c(C(=O)/C=C/c2ccccc2)c(OC)c1OCCOCCBr</smiles>

33<smiles>CCOCCOc1c(OC)cc2oc(-c3ccccc3)cc(=O)c2c1OC</smiles>

34<smiles>CC(=O)Oc1c(OC(C)C)cc2oc(-c3ccccc3)cc(=O)c2c1OC(C)=O</smiles><smiles>CC(=O)Oc1c(O)cc2oc(-c3ccccc3)cc(=O)c2c1OC(C)=O</smiles>

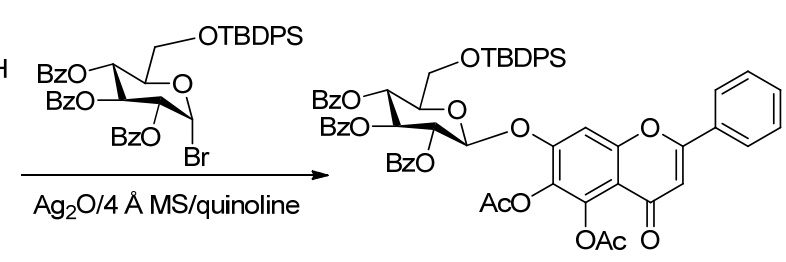

39

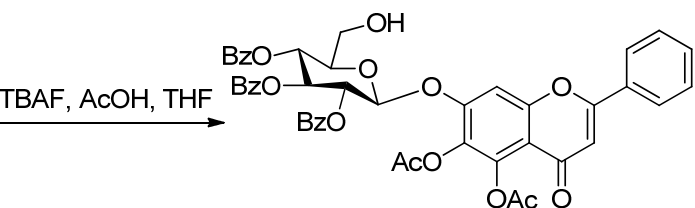

40

38

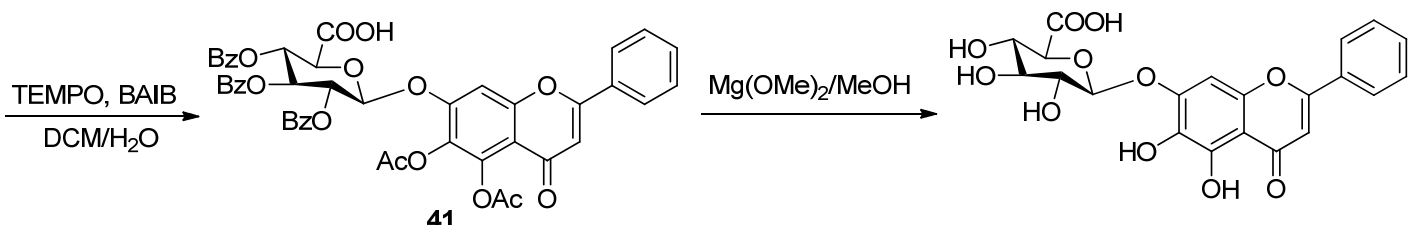

42

图式 6 黄芩苷的全合成路线

Scheme 6 Total synthetic route of baicalin

合成成为很有挑战性的工作 ${ }^{[64]}$. 邻苯二甲酰亚胺是经 典的相邻参与基, 通常邻苯二甲酰亚胺糖基卤化物的糖 基化反应倾向于生成 1,2-反式-2-氨基糖苷. 然而, 在上 述反应中, 以乙酰基保护的 $N$-邻苯二甲酰亚胺基-2-脱 氧- $D$-葡萄糖为糖基供体生成 1,2-顺式糖苷. 这可能是 由于发生 $\mathrm{S}_{\mathrm{N}} 2$ 反应, 在 $\mathrm{CHCl}_{3} / \mathrm{K}_{2} \mathrm{CO}_{3} / \mathrm{TBAB}$ 体系中, 没 有强有力的启动子可以使溴离子从糖基供体中脱离形 成反应性双环酰氧基鎓离子中间体. 此外, 在碱性 $\mathrm{CHCl}_{3} / \mathrm{K}_{2} \mathrm{CO}_{3} / \mathrm{TBAB}$ 体系中, 檞皮素- $\mathrm{C}-3-\mathrm{OH}$ 可能更具 亲核性, 并且其对糖基供体端位碳的有效攻击主要来自 卤素原子的相反方向. 上述在相转移催化法中, 以 $N$-邻 苯二甲酰亚胺基保护的糖基供体合成槲皮素 3-O-1,2-顺 式-2-氨基糖苷的方法, 值得进一步深入研究其机理, 为 合成 1,2-顺式糖苷提供参考.

\subsection{3 糖基三氯乙酰亚胺酯法}

由于有邻基参与效应(neighboring group participation), 糖基三氯乙酰亚胺酯法具有高立体选择性和高收 率的优点, 从而受到化学家们的重视. 近年来在寡糖和 糖苷的合成中得到了广泛的应用, 逐渐成为合成糖苷键 的首选方法, 但该方法在黄酮苷的合成中产率较低, 应 用较少. 目前, 催化三氯乙酰亚胺酯与受体连接的活化 剂主要有 $\mathrm{AgOTf}^{[65]} 、 \mathrm{BF}_{3} \cdot \mathrm{Et}_{2} \mathrm{O}^{[31]}$ 等路易斯酸.
由于 5-OH 与 4-C $=\mathrm{O}$ 形成氢键作用, 使得 5-羟基7,4'-二甲氧基黄酮直接与卤代糖或糖基三氯乙酰亚胺酯 的二糖糖基供体进行糖苷化反应得不到 5 位糖基化产 物. 因此, Arai 等 ${ }^{[66]}$ 在合成蕉香苷时, 首先设法合成 $\alpha / \beta$ 构型 5-羟基-7,4'-二甲氧基黄烷(53)糖基受体关键中间 体. 由于与氟代糖进行糖苷化反应, 得到极难分离的 5- $O$-糖苷和 6- $C$-糖苷的混合产物. 因此, 以糖基三氯乙 酰亚胺酸酯替代氟代糖, 在路易斯酸 $\mathrm{BF}_{3} \cdot \mathrm{Et}_{2} \mathrm{O}$ 催化下 进行糖苷化反应得到了 $\alpha / \beta$ 构型黄烷 5- $O$-糖苷关键反应 中间体(54), 最后经过 DDQ 氧化脱氢、碱水解去保护基 等步骤反应得到蒦香苷, 总收率为 $9.5 \%$ (反应关键步骤 Scheme 9).

文献报道 ${ }^{[67]}$, 通过相转移催化法和糖基三氯乙酰 亚胺酯法相结合, 合成了黄酮二糖苷高圣草素 7-O- $\beta-D-$ 芹菜糖(1/2)- $\beta$ - $D$ - 葡萄糖苷[ 又称檞寄生新苷 III (viscumneoside III)](60). 首先在 $\mathrm{CHCl}_{3} / \mathrm{KOH}$ 体系中, 使用 相转移催化剂 TBAB 催化 $\alpha / \beta$ 构型苄基乙酰基保护的溴 代葡萄糖与 4'-芐氧基-3'-甲氧基-5,7-二羟基二氢黄酮 (55)进行糖苷化反应，然后经过去乙酰基、亚茮基取代 等步骤得到关键中间体 4'- $O$-芐氧基高圣草素-7- $O-3$ - 芐 基-4,5-亚苄基- $\beta$ - $D$ - 葡萄糖苷(60)，糖基化产率为 $80 \%$. 由于乙酰化保护的溴代芹菜糖不稳定，在 $\mathrm{DCM} / 4 \AA$ 分子 


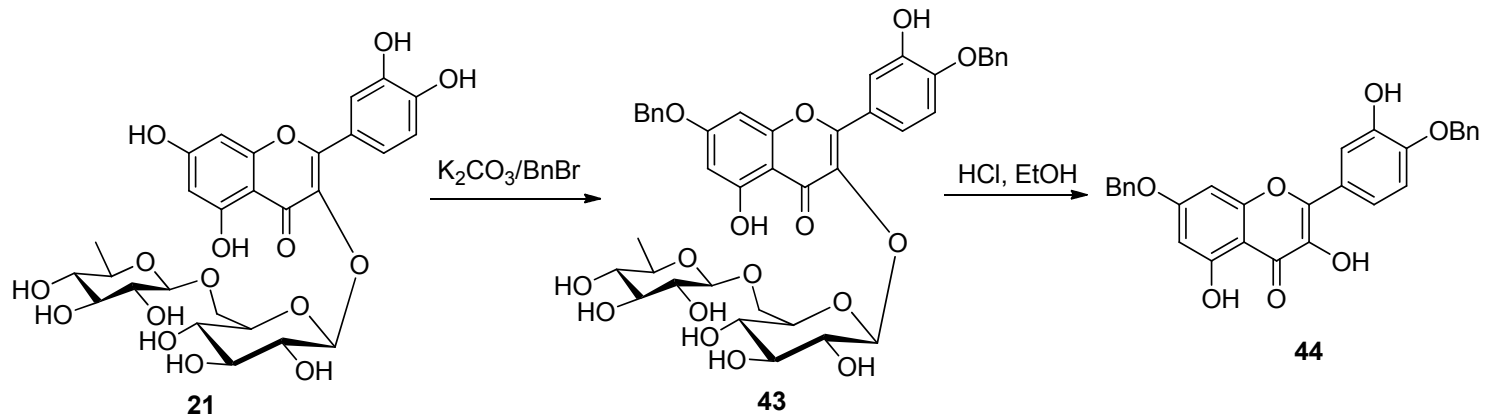

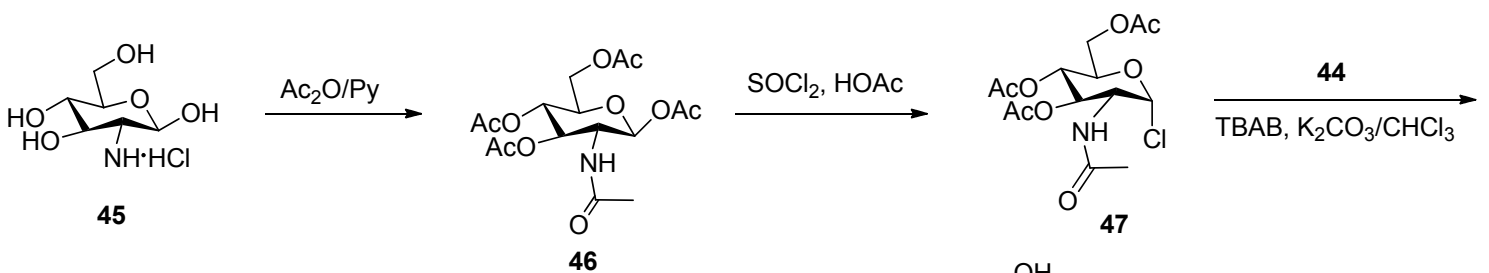

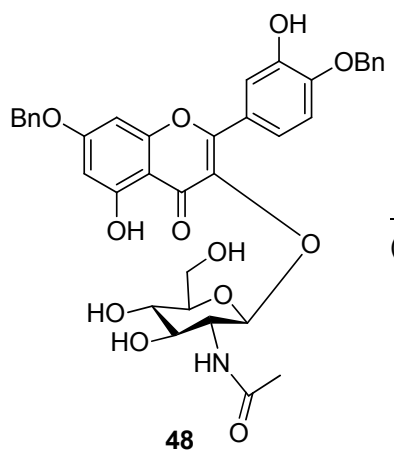<smiles>CC(=O)NC1C(O)C(O)C(O)C(O)C1Oc1c(-c2ccc(O)c(O)c2)oc2cc(O)cc(O)c2c1=O</smiles>

图式 7 葪皮素 3-O-1,2-反式糖苷的半合成路线

Scheme 7 Semi-synthetic route of quercetin 3-O-1,2-transglycoside

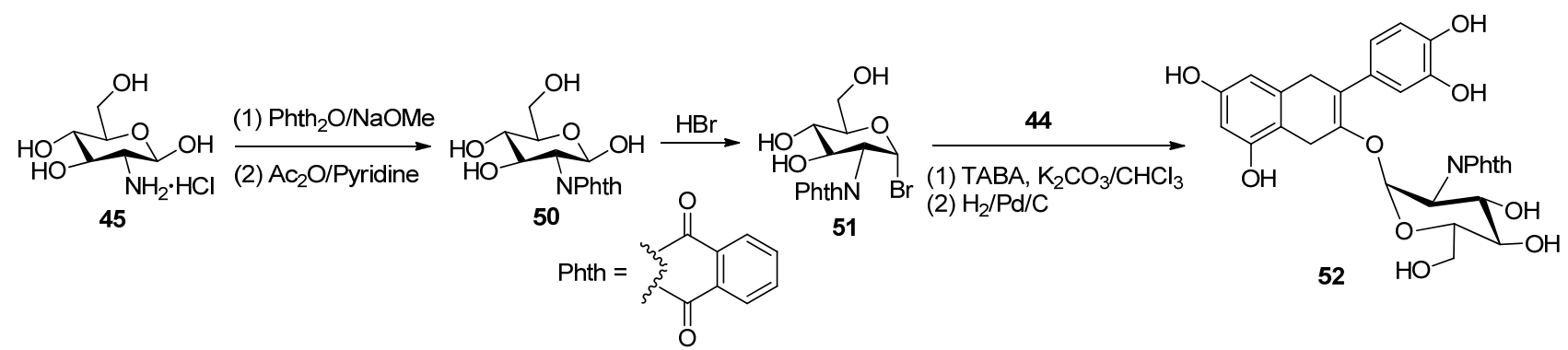

图式 8 觮皮素槲皮素 3-O-1,2-顺式糖苷的半合成路线

Scheme 8 Semi-synthetic route of quercetin-3-O-1,2-cis-glucoside

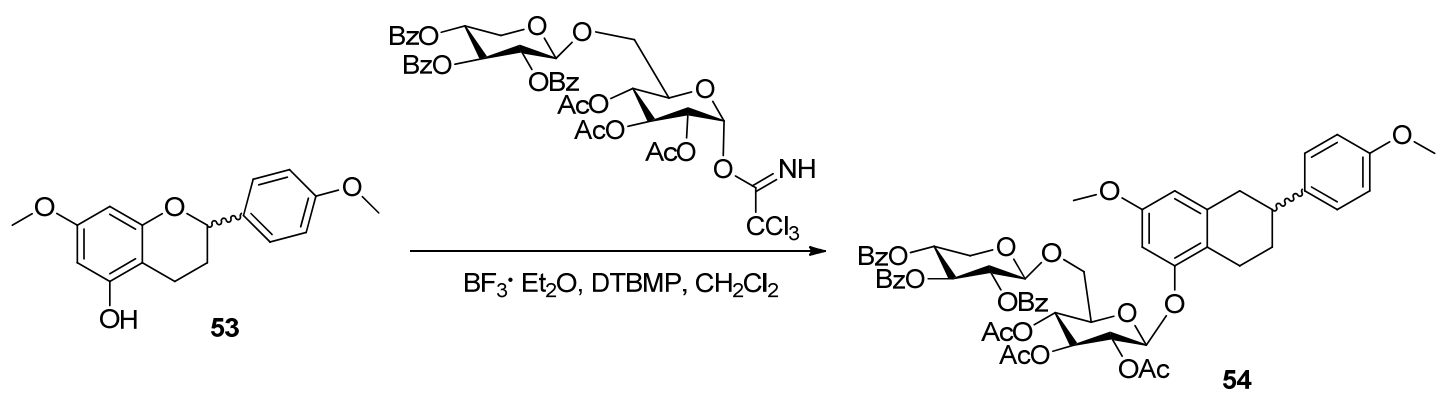

图式 9 三氯乙酰亚胺酯法合成蕉香苷

Scheme 9 Synthesis of agalloside by trichloroacetimidate 
筛体系中, 以 $\mathrm{TMSOTf}$ 或 $\mathrm{BF}_{3} \cdot \mathrm{Et}_{2} \mathrm{O}$ 为催化剂和 $\alpha / \beta$ 构型 端头乙酰化的澳代芹菜糖糖基供体进行糖苷化反应, 得 不到糖苷产物. 因此, 将糖基供体替换成 $\alpha / \beta$ 构型糖基 三氯乙酰亚胺酯进行糖苷化反应，再去保护基后得到了 目标产物高圣草素-7- $O-\beta$ - $D$ - 芹菜糖(1/2)- $\beta$ - $D$ - 葡萄糖苷 (60), 糖基化产率 60\% (Scheme 10). 在二糖苷合成反应 中, 当溴代糖不稳定以及反应性非常低的端基为乙酰基 的糖基给体不适用于糖苷化合成时，具有高反应性和可 靠性的糖基三氯乙酰亚胺酯也是一个可供选择的糖基 供体.

\subsection{4 金催化的邻炔基苯甲酸糖基酯法}

传统的糖苷化方法合成黄酮 5- $O$-糖苷产率特别低, 甚至不反应, 原因是由于 $5-\mathrm{OH}$ 与 $4-\mathrm{C}=\mathrm{O}$ 形成分子内氢 键, 使得 5-OH 反应活性非常低 ${ }^{[66]}$. 而金催化的邻炔基 苯甲酸糖基酯法由于它们参与形成强的分子内氢键, 使 得黄酮类 $5-\mathrm{OH}$ 反应活性大大提高，从而实现了黄酮 5-OH 高选择性、高效糖基化. 虽然 $\mathrm{Au}(\mathrm{I})$ 离子容易被还 原为沉淀, 使金催化剂失活, 且来源昂贵, 但是由于其
具有黄酮 5-OH 高选择性、高效糖基化的特点，使其成 为一种合成黄酮 5- $O$-糖苷的可选择方法. Sun 等 ${ }^{[68 \sim 70]}$ 通 过在 $\mathrm{PPh}_{3} \mathrm{AuNTf}_{2}$ 催化下, 以邻炔基苯甲酸糖基酯(62) 作为糖基供体，与选择性苄基、叔丁基二甲基硅氧基等 保护的山奈酚、檞皮素、芹菜素 5-OH 进行糖基化反应, 获得了山奈酚、槲皮素、芹菜素 5-O-糖苷, 糖苷化收率 高达 65\% 99\% (Scheme 11).

\section{2 黄酮碳苷的合成}

天然的黄酮碳苷的糖基通常与黄酮的 C-6 和 (或)C-8 位置连接, 如异牡荆素、牡荆素、牡荆苷、荭草 苷等. 目前合成黄酮碳苷链主要是两种方法. 第一种是 糖基供体直接与黄酮苷元及其衍生物糖基化, 主要应用 于半合成; 第二种是首先构建糖苷键后再合成黄酮部 分, 主要应用于全合成. 目前最常用合成黄酮碳苷的糖 苷链的方法是通过糖基供体与酚形成氧苷, 然后在路易 斯酸的作用下重排为碳苷, 这种反应简称为 $\mathrm{O} \rightarrow \mathrm{C}$ 重排 反应.

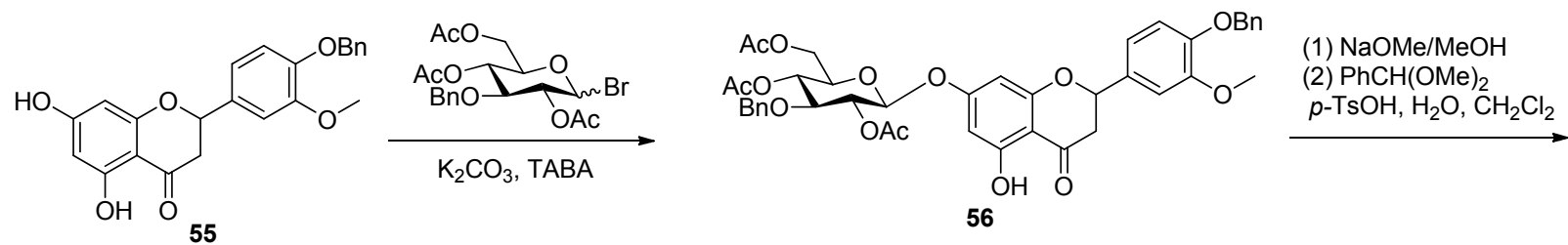

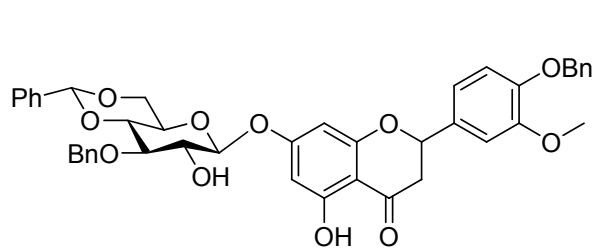

57

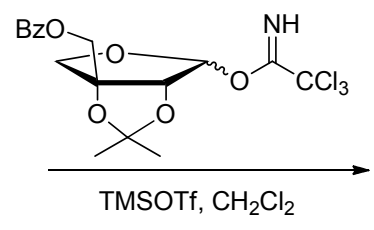

TMSOTf, $\mathrm{CH}_{2} \mathrm{Cl}_{2}$

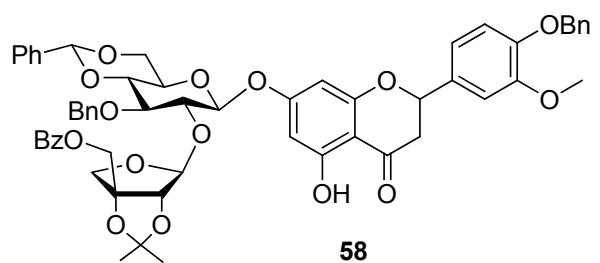

58

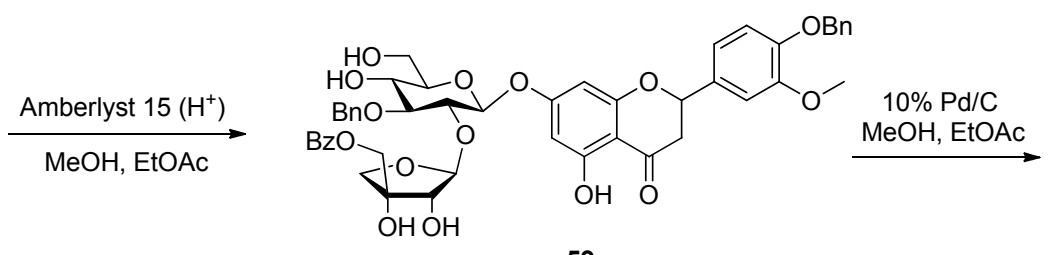

59

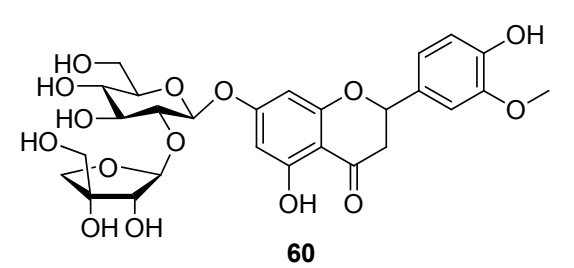

60

图式 10 槲寄生新苷的半合成路线

Scheme 10 Semi-synthetic route of viscumneoside

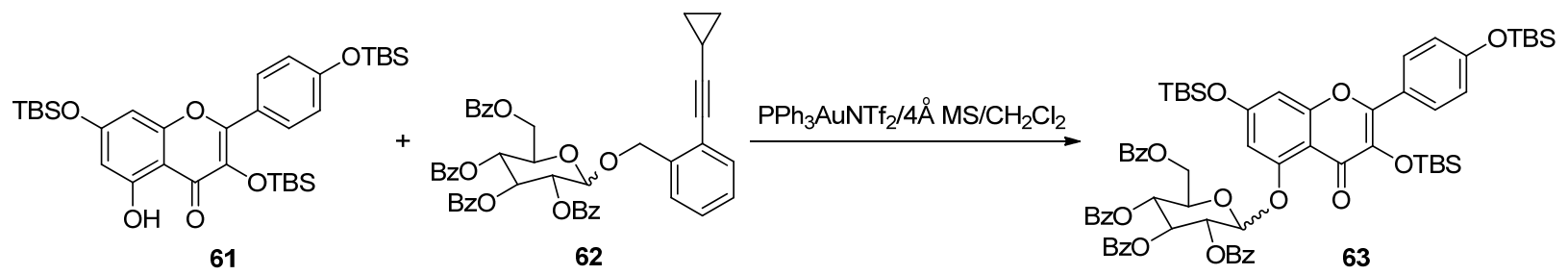

图式 11 金催化的邻炔基苯甲酸糖基酯法合成路线

Scheme 11 Synthetic route of gold-catalyzed $o$-alkynyl benzoate glycosyl ester 


\subsection{1 黄酮碳甘的全合成}

通过 $\mathrm{O} \rightarrow \mathrm{C}$ 糖苷重排方法合成黄酮苷具有相对可靠 的区域选择性优点, 即在酚羟基的邻位选择性地形成糖 苷. 黄酮碳苷全合成一般是以羟基苯乙酮及其衍生物为 原料如 2,4,6-三差基苯乙酮及其衍生物, 在路易斯酸如 $\mathrm{TfOH}$ 的作用下, 与糖基供体糖苷化反应生成羟基苯乙 酮及其衍生物碳糖苷, 然后再与苯甲醛及其衍生物或苯 甲酰氯及其衍生物通过经典的 BK-VK 法、AFO 法或其 他方法合成黄酮骨架部分.

对于黄酮 8-C-糖苷的合成，一般是以 2,4,6-三羟基 苯乙酮为原料, 进行区域选择性保护 2 或 2,4 位酚羟基, 如苄基化、甲氧基化等. 刺果素苷是天然黄酮-8- $C$-糖苷 化合物, 具有良好抗肿瘤 ${ }^{[71,72]}$ 、抗炎 ${ }^{[73]}$ 等活性, 然而其 在植物中含量极低, 从干燥的竹节草根和根茎提取分离 获得的刺果素苷产率仅为 $0.26 \%{ }^{[71]}$, 其化学合成受到了 化学家重视. 文献报道, 首先通过在 NIS/TfOH 酸性条 件下, 2 -羟基-4,6-二甲氧基苯乙酮(64)与 $\alpha / \beta$ 构型洋地黄 毒糖糖基供体通过 Fries 型 $\mathrm{O} \rightarrow \mathrm{C}$ 重排反应构建 $C$-芳基 糖苷键, 得到关键中间体 $\alpha$-羟基芳基 $C$-糖苷 $(65)$, 然后 以 EDC/DMAP 介导、催化与 4-芐氧基苯甲酸进行酯化 反应, 再通过 $\mathrm{BK}-\mathrm{VK}$ 重排得到 $\beta$-丙二酮中间体 (67), 以 CSA 介导环化脱水反应构建黄酮结构单元, 最后去茮 基化和苯甲酰基化合成了刺果素苷(69), 总收率为 $8.3 \%{ }^{[74]}$ (Scheme 12).

而对于黄酮 6- $C$-糖苷的合成, 一般是区域选择性保 护 2,4,6-三羟基苯乙酮 4 位或 4,6 位酚羟基. Wang 等 ${ }^{[75]}$ 通过在 $\mathrm{Sc}(\mathrm{OTf})_{3} / \mathrm{PhMe} / 4 \AA$ 分子篎体系中, 以 2,6 -二羟 基-4-芐基-苯乙酮为原料，通过类似上述合成刺果素苷
的反应步骤，获得了具有良好降血糖活性的杨桃黄酮 A.

牡荆苷-2 是天然黄酮 6,8-二糖苷, 具有良好抗肿

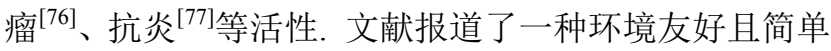
合成牡荆苷-2 的方法. 首先在 $\operatorname{Sc}(\mathrm{OTf})_{3}$ 水溶液下, 通过 无保护的 $D$-葡萄糖和 2,4,6-三羟基苯乙酮一步反应，获 得的 $2,4,6$-三羟基苯乙酮-3,5-二- $C-\beta-D$-葡萄糖苷关键中 间体与 $2,4,6$-三羟基苯乙酮-3- $C-\beta-D$-葡萄糖苷副产物, 再经过选择性茮基化、与对氧苄基苯甲醛发生 AFO 反 应等步骤获得了牡荆苷- $2^{[78,79]}$. 但该方法糖基化区域选 择性低、产率较低，且在二糖苷合成时，只适用于具有 相同糖基的合成. 2018 年, 文献报道一种利用 1,3,5-三 氟苯 $(70)$ 为原料构建二 $-C$-糖苷关键中间体 $(73)$, 后期再 通过氧官能团对氟原子进行芳香亲核取代合成黄酮 6,8二- $C$-糖苷的独特方法. 首先在 $t-\mathrm{BuLi} \cdot \mathrm{Et}_{2} \mathrm{O}$ 体系中, 将 三氟苯理盐化，与 $D$-葡糖酸内酯糖基供体进行糖基化， 然后再进行硅烷还原得到单 $C$-糖苷, 重复相同的过程 得到二- $C$-糖苷. 接着, 与 $\alpha, \beta$-不饱和 Weinreb 酰胺构建 查耳酮后，再通过氧亲核试剂亲核取代氟化物构建黄酮 骨架，然后再脱苄基得到告荆苷-2 (78) ${ }^{[80]}$ (Scheme 13).

\subsection{2 黄酮碳苷半合成}

与黄酮氧苷的半合成相比, 黄酮碳苷的半合成研究 相对较少, 主要是碳一碳键的构建比碳一氧键的构建困 难，直接糖基化的产率很低. 文献报道 ${ }^{[79]}$, 在 $\mathrm{CH}_{3} \mathrm{CN} /$ $\mathrm{H}_{2} \mathrm{O}$ 体系中, 以 $\mathrm{Sc}(\mathrm{OTf})_{3}$ 为催化剂, 直接以无保护的 $\alpha / \beta$ 构型柚皮素和 $D$-葡萄糖进行糖基化反应, 得到了 $\alpha / \beta$ 构 型柚皮素 6,8-C-二葡萄糖苷(收率 $17.3 \%$ ), 然后经过乙 酰化、DDQ 氧化脱氢、去乙酰化等步骤获得了牡荆苷-2.

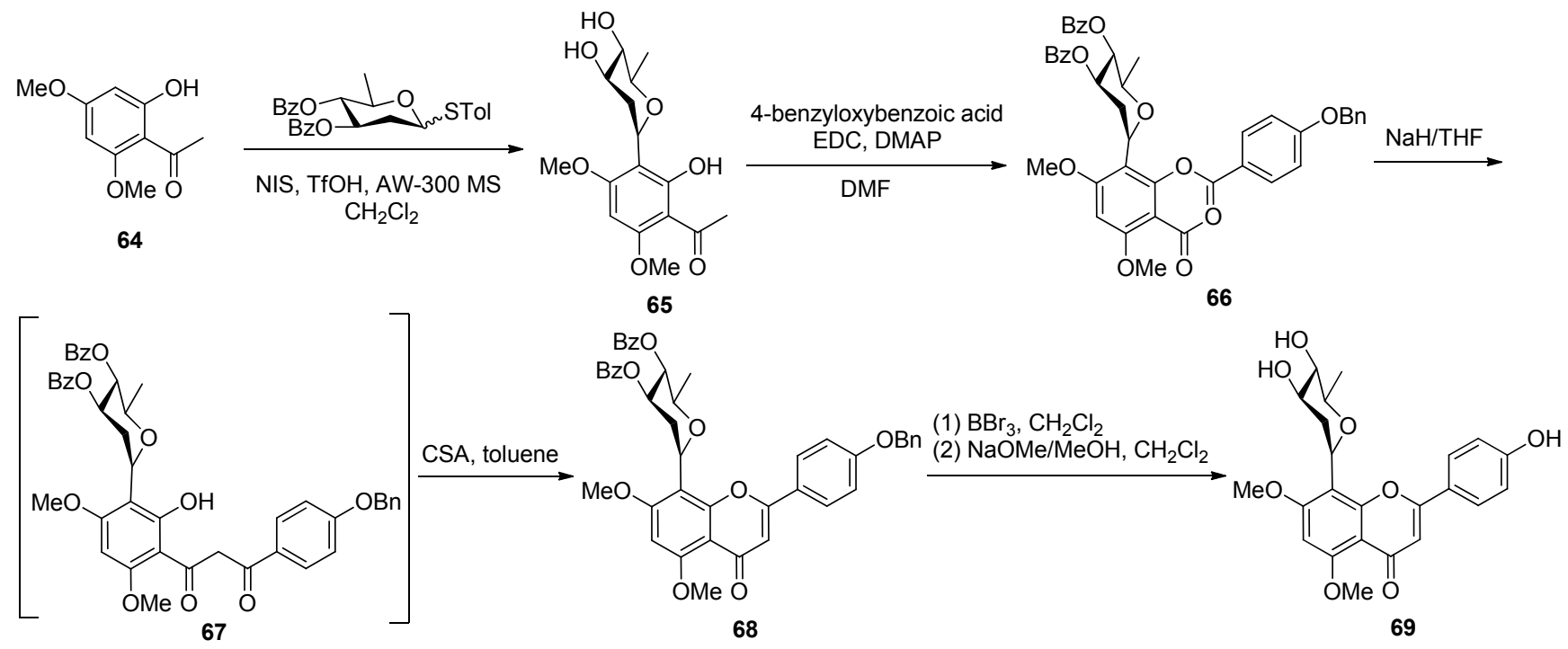

图式 12 刺果素苷的全合成路线

Scheme 12 Total synthetic route of aciculatin glycoside 

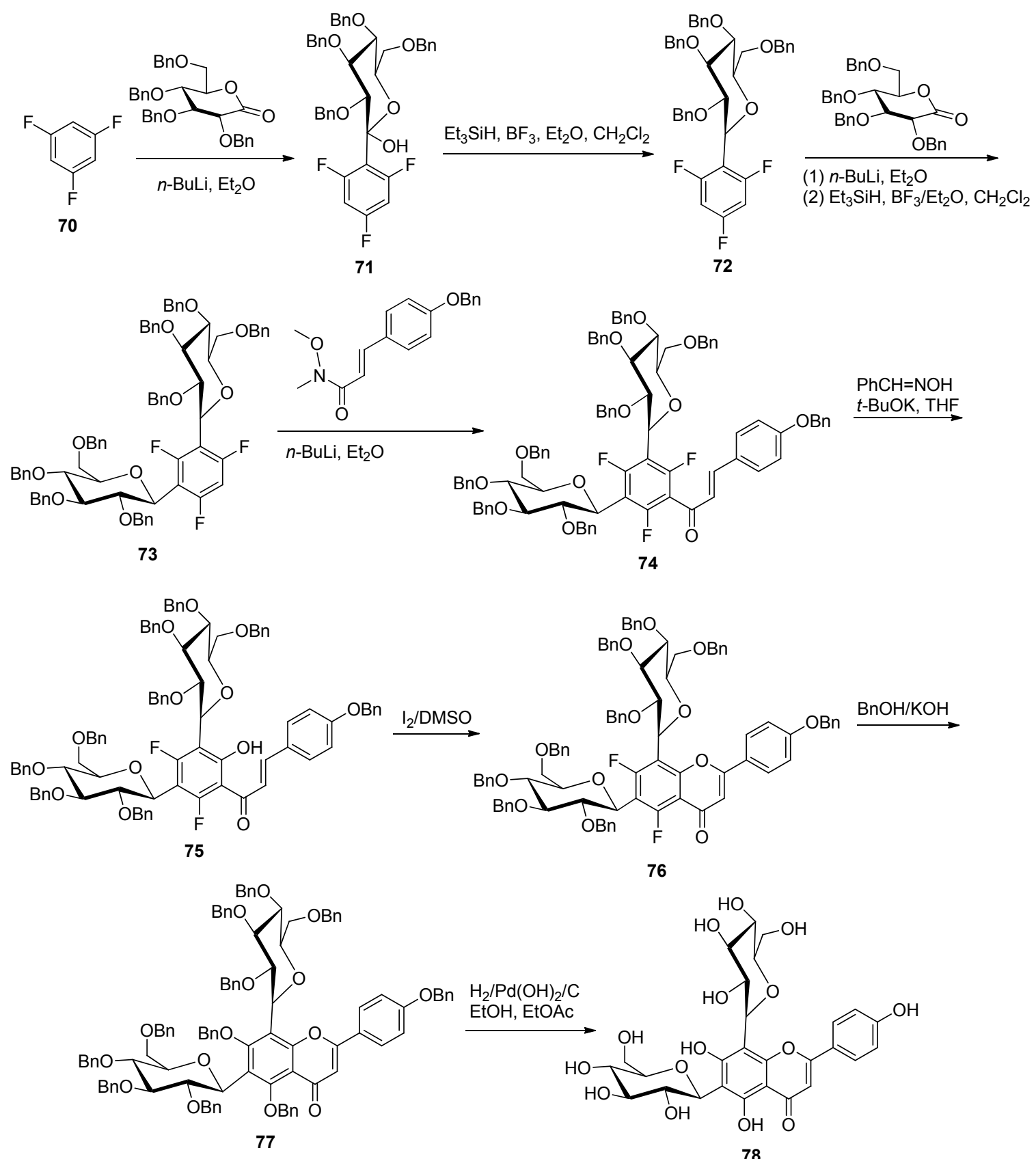

76

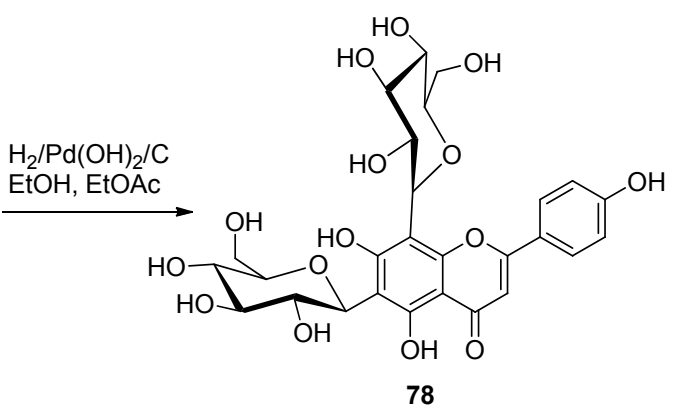

图式 13 牡荆苷-2 的全合成路线

Scheme 13 Total synthetic route of vitexin-2

在该反应中, 存在糖基化区域选择性差、产率低, 糖基 化副产物多, 糖苷化产物分离困难等缺点, 其中副产物 包括单糖和一些尚未鉴定的其他副产物, 单糖苷产物与 二糖苷产物相当(单糖苷总产率约 $15 \%$ ), 并且二糖苷产 物只适用于相同糖基的二糖苷化合物的合成. 因此, 对 上述方法进行改进, 利用柚皮素 7 位羟基反应活性最高 的特点, 依次通过选择性 7 位苄基化、乙酰基化、还原 4 位羰基、选择性去 5 位乙酰基获得的 5 位羟基黄烷衍 生物糖基受体关键中间体，再与苄基保护的糖基三氯乙 酰亚胺酯糖基供体进行区域选择性 6 位基化反应获得黄
烷 6-C-单糖苷关键中间体，接着，去 7 位苄基，再区域 选择性进行 8 位糖基化获得黄烷 6,8-C-二糖苷关键中间 体，最后再经过对 4 位 $\mathrm{C}$ 氧化羟基化和羰基化、去乙酰 基等反应获得系列黄酮 6,8-C-糖苷 ${ }^{[78]}$. 通过改进后, 糖 基化区域选择性、糖苷化产率得到提高(产率 55\% $79 \%$ )，不仅适用于相同糖基的二糖苷化合物合成，而且 也适用于不同糖基的二糖苷化合物的合成.

\section{3 酶催化生物合成黄酮苷}

黄酮苷的化学合成文献报道较多, 但总体产率不 
高、选择性及对底物适应性差, 步骤多且产物分离困难, 且许多糖苷化方法适用范围均有一定的局限性, 难以满 足糖苷键的多样性. 近年来, 随着生物技术的发展, 人 们对酶催化生物合成黄酮苷的研究越来越广泛, 酶催化 生物合成具有高立体选择性、高效性等优点, 除此之外, 酶催化生物合成糖苷, 不仅避免了繁琐的保护和去保护 等复杂的反应步骤, 而且反应条件温和、对环境友好, 所得产物纯度高、收率高但酶不易获得、价格昂贵. 目 前酶催化生物合成黄酮苷最常用的酶有两种: 糖基转移 酶 (glycosyltransferases, GTs) 和糖苷合成酶 (glycosynthase), 而糖基转移酶又主要包括氧糖基转移酶 ( $O$-glycosyltransferases, OGTs) 和碳糖基转移酶 ( $C$-glycosyltransferases, CGTs).

\section{1 糖基转移酶}

糖基转移酶催化活性糖基核苷磷酸糖(主要是尿苷 二磷酸糖或胸腺嘧啶二磷酸糖)转移到糖基受体, 如蛋 白、核酸、葟糖、脂, 以及二级代谢产物如黄酮、抗生 素等分子. 目前, 由于活性糖供体核苷磷酸糖价格昂 贵、所用酶的不易获得等缺点限制了其广泛的使用及工 业化大生产 ${ }^{[81]}$.

\section{1 .1 氧糖基转移酶}

人们对氧糖基转移酶催化合成黄酮苷的研究, 主要 是对酶糖基化的区域选择性、底物、活性糖基给体等方 面研究.

目前, 大多数氧糖基转移酶是催化活性糖基与黄酮 $\mathrm{A}$ 环的 7-O 和(或)C 环的 3-O 和(或)B 环的 3'-O 或 4'-O 连接 $\left.{ }^{[82} 85\right]$. 文献报道, 来自地衣芽狍杆菌 DSM 13 的氧 糖基转移酶 $(\mathrm{YjiC})$, 以 UDP- $\beta$ - $D$ - 葡萄糖为糖基供体，区 域选择性葡萄糖苷化位置为黄酮 3-O. 此外, 以另外四 种不同核苷酸的糖基给体代替 UDP- $\beta$ - $D$ - 葡萄糖葡对活 性糖基特异性研究发现, 五种不同类型的 NDP- $D$-葡萄 糖可作为糖基转移酶反应的供体, 但是在不同的核苷酸 葡萄糖基供体中底物转化率不同, 其中 ADP- $\beta-D$ - 葡萄 糖、GDP- $\beta-D$ - 葡萄糖和 UDP $-\beta-D$ - 葡萄糖的转化率 (约 $90 \%$ ) 几乎相等, 而 TDP- $\beta-D$-葡萄糖约为 $75 \%$ 和 CDP- $\beta$ $D$-葡萄糖约为 $67 \%{ }^{[86]}$. 然而, 有文献报道上述酶 $(\mathrm{YjiC})$ 催化 UDP- $\beta$ - $D$ - 葡萄糖与芹菜素进行糖苷化反应, 得到 芹菜素 4'-O-葡萄糖苷、芹菜素 7- $O$-葡萄糖苷、芹菜素 $4^{\prime}, 7-O$-二葡萄糖苷 ${ }^{[87]}$. 上述糖基化的结果不同的原因可 能是芹菜素没有 3-O, 因此该酶区域选择性糖苷化的位 置为 7-O 和 4'-O. 由此说明氧糖基转移酶催化的活性位 点与底物有关, 当底物黄酮含 3-O 时, $\mathrm{YjiC}$ 酶催化糖苷 化的区域选择性位置为 3-O; 当底物黄酮不含 3-O 时, 该酶催化糖苷化的区域选择性位置为 7-O 和 4'-O. 在对 氧糖基转移酶 CsUGT76F1 催化合成黄酮的研究中发现,
该酶可以催化合成黄酩 3- $O 、 7-O 、 3,7-O$-葡萄糖糖基苷 和 7- $O$-鼠李糖糖苷, 而对该酶底物特异性的研究表明, 对黄酮具有广泛的底物特异性, 包括存在于相橘属物种 中的柚皮素、橙皮素、香叶木素、山奈酚和槲皮素等黄 酮 ${ }^{[8]}$. 上述例子说明部分微生物来源的氧糖基转移酶 可催化黄酮的多个 $\mathrm{OH}$ 位点, 这是造成氧糖基转移酶底 物区域选择性差的主要原因. 因此, 人们可根据底物特 点及糖基化位点进行氧糖基酶选择，同时提示能否通过 基因工程技术对控制糖基转移酶其他位点进行基因敲 除，或通过某种手段、方法抑制该酶其他活性位点，以 提高对底物的区域选择性糖基化.

2016 年首次报道来自真菌毛霉 (Mucor hiemalis) 的 氧糖基转移酶 MhGT1, 通过以 UDP-葡萄糖作为糖供体, 酚类化合物作为底物, 对 MhGT1 的底物特异性进行研 究发现，该酶对黄酮类、香豆素类等酚类化合物具有较 高氧糖基化的能力, 尤其是对异戊烯化酚类化合物的区 域特异性和活性更高 ${ }^{[89]}$. 异戊烯基黄酮的 $C$-异戊烯基 侧链的存在大大加强化合物的亲脂性, 使得化合物更容 易穿过脂溶性的细胞膜与靶蛋白相结合，显著提高黄酮 的生物活性. 而黄酮苷元水溶性较低, 糖基化可增加水 溶性，因此可利用氧糖基转移酶 MhGT1 对异成烯基酚 类的区域特异性和活性更高的特点，进行异戊烯基黄酮 苷(如具有良好抗肿瘤活性的淫羊蒦苷等)生物合成.

由于大部分植物来源的糖基转移酶是以 UPD-葡萄 糖作为活性糖基供体, 使得转移酶催化除葡萄糖以外的 糖基供体与黄酮连接变得更具有挑战性. 后来人们把目 标转向对微生物的研究, 如携带植物 UGT 的大肠杆菌, 通过基因工程改造 UGT 的糖选择性，寻找其他的糖基 供体. 近年来, 通过基因工程的途径合成了多个天然的 黄酮苷, 如黄酮 $O$-半乳糖苷 ${ }^{[84]}$ 、黄酮 $O$ - 鼠李糖苷 ${ }^{[85]}$ 、 黄酮 $O$-木糖苷 ${ }^{[90]}$ 等. 来自芽孢杆菌 DSM 13 的氧糖基转 移酶 $\mathrm{GT}(\mathrm{YjiC})$ 催化由 $p g i 、 z w f$ 和 $g a l U$ 基因缺陷的大肠 杆菌 BL21(DE3)产生的 dTDP-1-鼠李糖、dTDP- $D$-维他 命胺、dTDP-4-氨基 4,6-二脱氧- $D$-半乳糖和 dTDP-3-氨 基 3,6-二脱氧- $D$-半乳糖这四种 dTDP-脱氧糖与黄酮醇 进行糖苷化, 结果只有 dTDP-1-鼠李糖可以与黄酮醇 3-O 发生糖苷化生物转化反应, 得到黄酮 3- $O$ - 鼠李糖 苷 ${ }^{[91]}$. 此外，通过基因工程的途径还合成了一些自然界 未被发现的黄酮氧苷 ${ }^{[92]}$. 文献报道, 以 UDP- $N$-乙酰葡 糖胺作为糖供体，在携带糖基转移酶 AtUGT78D2 的大 肠杆菌中进行槲皮素糖苷的生物合成, 得到了新的黄酮 苷檞皮素 3-O- $N$-乙酰葡糖胺. 并且, pgm 和 galU 基因缺 失的大肠杆菌突变菌株与野生型大肠杆菌 BL21(DE3) 对檞皮素 3-O- $N$-乙酰葡糖胺的生成量相差较大, 其中野 生型 DE3、pgm 突变体和 galU 突变体产生的䚞皮素 
3-O-NAG 与槲皮素 3- $O$-葡萄糖苷的比分别为 $32: 68$ 、 $65: 35$ 和 $93: 7$, 由此说明了 pgm 突变体和 galU 突变 体均可促进产生葪皮素 3-O- $N$-乙酰葡糖胺, 但 galU 突 变体促进效果最明显, 比野生型 DE3 多三倍, 产生 $380.7 \mathrm{mg} / \mathrm{L}$ 葪皮素 3-O- $N$-乙酰葡糖胺 ${ }^{[93]}$. 通过基因工程 技术对微生物的改造, 大大地丰富了活性糖基的来源, 从而扩充了黄酮碳苷的种类和数量, 具有重要意义.

\subsection{2 碳糖基转移酶}

人们在碳糖基转移酶催化合成黄酮苷的研究中, 主 要是对酶催化糖基化的底物、活性位点、植物来源等方 面研究.

研究发现, 在谷物黄酮 $C$-糖苷的生物合成中, 黄酮 本身不是 $C$-糖基化的直接底物, 而是由一类黄烷酮 2差弪化酶 FNS II 催化形成的 2-羟基黄烷酮中间体 ${ }^{[94,95]}$. 然 而, 在其他植物中发现了可催化黄酮底物进行直接糖基 化的糖基转移酶, 如 UGT708D1、UF6CGT1 等 ${ }^{[96,97]}$. 文 献报道 ${ }^{[97]}$, 来自大豆(Glycine max) 的碳葡糖基转移酶 UGT708D1 和来自龙胆草(Gentiana triflora)的碳葡糖基 转移酶 UF6CGT1, 催化黄酮白杨素和木犀草素与葡萄 糖直接糖基化生成相应 6- $C$-葡萄糖苷. 此外, 通过生物 工程获得重组大肠杆菌, 进行引入对外源的 UPD-葡萄 糖生物合成基因、促进葡萄糖扩散蛋白以及发酵罐规模 的因素对黄酮底物转化为碳糖苷化的影响研究, 结果发 现外源的 UPD-葡萄糖生物合成基因、促进葡萄糖扩散 蛋白以及扩大发酵罐规模, 均有利于提高 $C$-糖基转移 酶催化底物转化为 $C$-糖苷的转化率.

在对来自菾麦(Fagopyrum esculentum $\mathrm{M}$ )的碳糖基 转移酶 UGT708D1 和大豆(Glycine max) 的碳糖基转移酶 $\mathrm{UGT} 708 \mathrm{C} 2$ 直接和间接进行碳糖基化研究中 ${ }^{[98]}$, 首先通 过基因工程重建酵母, 使其产生一些相关的 CGT 底物: 黄烷酮柚皮素、圣草酚、黄酮芹菜素和木犀草素, 然后 再分别将黄烷酮 2-羟化酶 UGT708C2 $2^{[95]}$ 、 OsCYP93G $2^{[99]}$ 、 $\mathrm{SbCYP} 93 \mathrm{G} 3^{[100]}$ 与碳糖基转移酶 UGT708D1 或 UGT708C2 的组合进行黄烷酮柚皮素、圣 草酚底物间接糖基化, 分别获得了 $6-C$ - 葡糖苷黄酮异牡 荆素、 $8-C$ - 葡糖苷黄酮告荆素和 $6-C$ - 葡糖苷异荭草素、 $8-C$ - 葡糖苷荭草苷, 其中产黄烷酮柚皮素底物的酵母菌 组生成 6- $C$-葡萄糖苷为主, 而产圣草酚底物的酵母菌组 生成 8- $C$-葡萄糖苷为主. 而以来自龙胆 (Gentiana triflora)的碳糖基转移酶 GtUF6CGT1 进行芹菜素、木犀草素 底物直接糖基化, 仅产生 $6-C$-葡糖苷, 与之前报道结果 相一致 ${ }^{[96]}$, 且 6- $C$-葡糖苷黄酮异牡荆素的产量超过 200 $\mathrm{mg} / \mathrm{L}$. 上述报道中, 碳糖基转移酶 UGT708D1、 $\mathrm{UGT} 708 \mathrm{C} 2$ 间接糖基化的糖基化位点及底物对糖基化 位点影响的机理仍需进一步研究, 通过基因工程手段,
使重建酵母菌株产生单一糖苷产物. 而含碳糖基转移酶 GtUF6CGT1 的重组酵母菌直接糖基化位点为 6-C, 使通 过酵母发酵生产异荭草素、异告荆素成为可能.

在 2-羟基黄烷酮碳葡萄糖基转移酶 UGT708D1 的 活性位点的研究中, 发现其三个氨基酸残基 His20, Asp85 和 Arg292 位于 $C$-葡糖基化活性位点, 且在进化 上是保守的. 此外, 用丙氨酸取代 Asp85 或 Arg292 破坏 了碳葡萄糖基转移酶活性，但是用丙氨酸取代 His 20 , 使碳葡萄糖基转移酶活性转变为氧葡萄糖基转移酶活 性 ${ }^{[101]}$. 天然植物来源的黄酮 $C$-糖苷的糖链多位于 $6-\mathrm{C}$ 和(或)8-C, 提示植物来源的碳糖基转移酶的活性位点 有限，有希望通过生物工程利用氧糖基转移酶(O-GTs) 多样性开发新的碳糖基转移酶 ${ }^{[102]}$. 植物来源的糖基转 移酶的区域活性位置与天然植物来源的黄酮 $C$-糖苷多 位于 6-C 和(或)C-8 是相一致的. 文献报道, 来自植物山 蚂蝗的碳糖基转移酶 OsCGT 催化 2-羟基黄烷酮中间体 与 UDP-葡糖、UDP-半乳糖和 UDP-阿拉伯糖活性糖基 转化, 得到了系列的 6-C、8-C 和 6,8-C 糖基黄酮 ${ }^{[103]}$; 来 自金桔(Fortunella crassifolia)和柑橘(Citrus unshiu)的碳 糖基转移酶 FcCGT(UGT708G1)和 CuCGT(UGT708G2) 参与黄酮 $6,8-C$-葡萄糖苷生物合成 ${ }^{[104]}$.

在 2014 年前人们仅从水稻和玉米等单子叶植物中 发现碳糖基转移酶, 直到 2014 年 Taguchi 等 ${ }^{[105]}$ 报道了 从双子叶荞麦 (Fagopyrum esculentum $M$ ) 中鉴定了碳葡 萄糖基转移酶基因, 从菾麦幼苗中分离纯化了两种同工 酶 FeCGTa(UGT708C1) 和 FeCGTb(UGT708C2) 及其 cDNA, 丰富了 $C$-糖基转移酶的植物来源. 通过对不同 的组织器官来源的 RNA 研究发现, 这两种酶基因在种 子萌发期间在子叶中特异性表达. 此外, 对酶底物的研 究发现, 两种 $C$-糖基酶均表现出对 2-羟基黄烷酮、二氢 查尔酮、三羟基苯乙酮和其它相关化合物的 $C$-葡糖基化 活性，其底物的化学结构类似于 2,4,6-三羟基苯乙酮, 这对于结构多样性的黄酮 $C$-糖苷的合成具有巨大的吸 引力.

\section{2 糖苷合成酶}

于 1998 年 5 月, Withers 等 ${ }^{[106]}$ 最早研究报道糖苷合 成酶，同年 11 月 Planas 等 ${ }^{[107]}$ 报道了第一个内切葡聚糖 酶突变的内切糖苷合成酶, 同时, Moracci 等 ${ }^{[108]}$ 报道了 嗜热糖苷合成酶, 从此以后, 在国际范围内引起人们对 糖苷合成酶的研究. 糖苷合酶是通过基因工程的亲核试 剂定点诱变构型保持糖苷酶产生的酶，由于其不能水解 产物, 解决了糖苷合成可逆反应造成的产物水解问题, 可以从根本上解决黄酮化学合成产率低的问题, 但主要 限于氟代糖作糖基供体. 与糖基转移酶催化糖苗化合成 相比, 糖苷酶催化糖苷化合成具有底物糖基供体廉价、 
易得等优点. 目前, 糖苷合酶主要用于寡糖、多糖、鞘 糖脂等合成 ${ }^{[109 ~ 111]}$, 但对于黄酮苷的合成报道较少.

2003 年首次报道特异腐质霉 Cel7B E197S 突变体 是糖苷合酶催化剂 ${ }^{[112]} .2007$ 年 Yang 等 ${ }^{[113]}$ 以 20 种糖基 供体和 80 种黄酮糖基受体对糖苷合酶特异腐质霉 Cel7B E197S 突变体研究发现, 该酶可催化黄酮化合物, 如黄芩素、木犀草素、非瑟素、槲皮素与唯一有活性的 $\beta$ 构型的二乳糖基氟化物( $\mathrm{LacF}$ )糖基给体发生反应，得 到相应黄酮 4'- $O$-二糖苷或黄酮 6- $O$-二糖苷, 收率 $72 \% \sim 95 \%$ (Scheme 14). 当黄酮 B 环存在对二酚羟基 时, 特异腐质霉 Cel7BE197S 突变体糖苷酶催化与乳糖 糖基化得到黄酮 4'- $O$-二糖苷; 当 $\mathrm{B}$ 环不含对二酚羟基 时, 但含有 6 位羟基时, 得到黄酮 6-O-二糖苷. 由此证 明了黄酮的 6-O 和 4'-O (B 环含对二酚羟基)是该酶催化 糖苷化反应的立体选择性和区域选择性的结构位置.

\section{4 展望}

目前两种经典的黄酮苷元的化学合成方法比较成 熟, 但仍然存在一些缺点, 如反应须经过保护、去保护
等步骤，使得反应步骤较冗长，副产物多等缺点，仍需 针对这些缺点进行改良以及开发更好的新技术和方法. 虽然糖苷化方法较多，但许多糖苷化方法适用范围均有 一定局限性，难以满足糖苷键的多样性，且糖苷化收率 低、结构性、区域选择性差等这些问题有待解决，这对 合成化学家来说仍是一个严峻的挑战. 而酶催化糖苷合 成具有较高的结构、区域选择性，且可避免繁琐的保护、 去保护等复杂步骤，但由于酶不易获得、价格昂贵、糖 基给体底物柔性差等缺点，限制了其目前应用。新方 法、新技术在黄酮苷合成方面的应用，将是黄酮苷合成 研究的发展趋势. 相信随着有机化学、药物化学的发展 以及新方法、新技术的出现，将使得黄酮苷化学合成实 现无保护基反应、提高化学选择性(chemoselectivity)和 区域选择性(Regioselectivity). 同时，随着生物技术的发 展，生物工程对目标基因的改造、对酶来源的挖掘和改 造将会解决酶的来源困难、价格昂贵的问题以及使糖基 供体柔性变得高，促进酶催化糖苷化方法应用于黄酮苷 的合成。
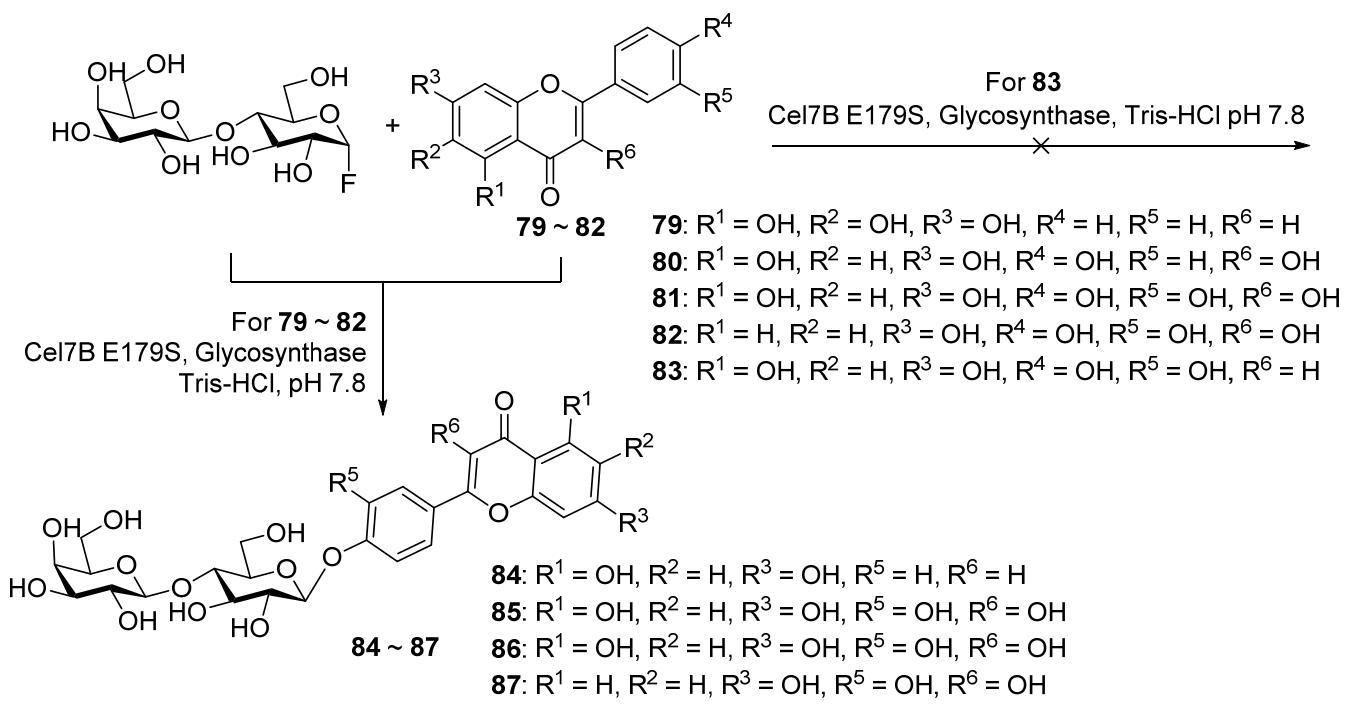

图式 14 Cel7B E179S 酶催化糖苷化反应路线

Scheme 14 Synthetic route of Cel7B E179S enzyme catalyzes the glycosidation

\section{References}

[1] Zhang, T. T.; Wang, M.; Yang, L.; Jiang, J. G.; Zhao, J. W.; Zhu, W. J. Funct. Foods 2015, 18, 235

[2] Shu, J.; Li, L.; Zhou, M.; Yu, J.; Peng, C.; Shao, F.; Liu, R.; Zhu, G.; Huang, H. Nat. Prod. Res. 2017, 23, 1.

[3] Huang, X.-X.; Wei, H.-L.; Pan, Y.-F. Food Ferment. Ind. 2013, 34, 140 (in Chinese).

(黄秀香，韦汉龙，盘玉芬，食品工业科技, 2013, 34, 140.)

[4] Ekuadzi, E.; Dickson, R.; Fleischer, T.; Annan, K.; Pistorius, D.; Oberer, L.; Gibbons, S. Phytother. Res. 2014, 28, 784.

[5] Jiang, X.-W.; Bai, J.-P.; Tian, X.; Zhao, Q.-C. Chin. Trad. Herb. Drugs 2016, 47, 726 (in Chinese).

(蒋晓文, 白俊鹏, 田星, 赵庆春, 中草药, 2016, 47, 726.)

[6] Shi, Q.; Guan, F.-Q.; Sun, H.; Zhao, Y.-Y.; Wang, M.; Zhang, J.-H.;
Feng, X.; Shan, Y. Food Sci. Technol. 2013, (6), 220 (in Chinese). (师琪, 管福琴, 孙浩, 赵友谊, 王鸣, 张建华, 冯煦, 单宇, 食 品科技, 2013, (6), 220.)

[7] Sun, L.; Peng, Q.; Qu, L.; Gong, L.; Si, J. Mol. Med. Rep. 2015, 11, 3094.

[8] Ekuadzi, E.; Dickson, S.; Fleischer.; Annan, K.; Pistorius, D.; Oberer, L.; Gibbons, S. Phytother. Res. 2014, 28, 784.

[9] Nawwar, M. A.; Hashem, A. N.; Hussein, S. A.; Swilam, N. F.; Becker, A.; Haertel, B.; Lindequist, U.; El-Khatib, A.; Linscheid, M. W. Pharmazie 2016, 71, 162 .

[10] Kumamoto, H.; Matsubara, Y.; Iizuka, Y.; Okamoto, K.; Yokoi, K. Agric. Biol. Chem. 2014, 49, 2613.

[11] Nguyen, P. H.; Dung, V. V.; Bing, T. Z.; Kim, Y. H.; Min, B. S.; Mi, H. W. Arch. Pharmacal Res. 2014, 37, 1394.

[12] Du, X.-G.; Geng, M.-Y. Sci. Life 2011, 23, 671 (in Chinese) 
(杜晓光, 耿美玉, 生命科学, 2011, 23, 671.)

[13] Montreuil, J. Adv. Carbohydr. Chem. Biochem. 1980, 37, 157.

[14] Winterburn, P. J.; Phelps, C. F. Nature 1972, 236, 147.

[15] Zhang, Y.-M. J. Northwest Univ. (Nat. Sci. Ed.) 2016, 46, 385 (in Chinese). (张勇民，西北大学学报 (自然科学版), 2016, 46, 385.)

[16] Ranjbari, J.; Mokhtarzadeh, A.; Alibakhshi, A.; Tabarzad, M.; Hejazi, M.; Ramezani, M. Curr. Pharm. Des. 2017, 23, 6019.

[17] Hofer, B. Appl. Microbiol. Biotechnol. 2016, 100, 4269.

[18] Huang, D.-D.; Chen, H.-H.; Li, M.-G.; Huang, J.-B.; Li, Y.-R.; Wei, G. Tradit. Chin. Drug Res. Pharmacol. 2017, 28, 73 (in Chinese). (黄丹丹, 陈欢欢, 黎梅桂, 黄俊涁, 李运容, 魏刚, 中药新药与 临床药理, 2017, 28, 73.)

[19] Obmann, A.; Zehl, M.; Purevsuren, S.; Narantuya, S.; Reznicek, G.; Kletter, C.; Glasl, S. J. Sep. Sci. 2015, 34,292.

[20] Qiu, L.; Jiao, Y.; Xie, J. Z.; Huang, G. K.; Qiu, S. L.; Miao, J. H.; Yao, X. S. J. Asian Nat. Prod. Res. 2013, 16, 589.

[21] Kondo, T.; Yoshida, K.; Oyama, K. I. Curr. Org. Chem. 2011, 15, 2567.

[22] Wang, Z. L.; Yang, L. Y.; Yang, X. W. Synth. Commun. 2013, 43, 22.

[23] Mei, Q.-G.; Yuan, W.-C.; Wang, C. Chin. J. Org. Chem. 2015, 35, 70 (in Chinese) (梅青刚, 袁伟成, 王淳, 有机化学, 2015, 35, 70.)

[24] Sun, J. S.; Laval, S.; Yu, B. Synthesis 2014, 46, 1030.

[25] Mohadeszadeh, M.; Iranshahi, M. Mini-Rev. Med. Chem. 2017, 17, 1377.

[26] Kitamura, K.; Ando, Y.; Matsumoto, T.; Suzuki, K. Chem. Rev. 2018, 118, 1495.

[27] Xiao, J.; Muzashvili, T. S.; Georgiev, M. I. Biotechnol. Adv. 2014, 32,1145 .

[28] Hofer, B. Appl. Microbiol. Biotechnol. 2016, 100, 4269.

[29] Ares, J. J.; Outt, P. E.; Kakodkar, S. V.; Buss, R. C.; Geiger, J. C. J. Org. Chem. 1993, 58, 7093.

[30] Song, G. Y.; Ahn, B. Z. Arch. Pharmacal Res. 1994, 17, 434.

[31] Wang, Q.-A.; Liao, T.-G.; Tang, J.-G.; Fan, H.-F. J. Hunan Univ. (Nat. Sci.) 2004, 31, 1 (in Chinese).

(汪秋安, 廖头根, 汤建国, 范华芳, 湖南大学学报(自科版), 2004, 31, 1.)

[32] Zacharia, J. T.; Hayashi, M. Carbohydr. Res. 2012, 348, 91.

[33] Kerl, T.; Berger, F.; Schmalz, H. G. Chemistry 2016, 22, 2935.

[34] Algarl, J.; Flynn, J. P. Proc. R. Ir. Acad. 1934, 42, 1.

[35] Oyamada. B. Chem. Soc. Jpn. 1934, 55, 2039.

[36] Oyamada, T. Tetrahedron 1935, 64, 988.

[37] Zhou, Q.; Wang, C.; Li, Y.-P.; Pu, W.-C. Chin. J. Appl. Environ. Biol. 2017, 24, 232 (in Chinese).

(周强, 王淳, 李玉萍, 蒲文臣, 应用与环境生物学报, 2017, 24, 232.)

[38] Shen, X.; Zhou, Q.; Xiong, W.; Pu, W.; Zhang, W.; Zhang, G.; Wang, C. Tetrahedron 2017, 73, 4822.

[39] Li, X.; Chen, G.; Zhang, X.; Zhang, Q.; Zheng, S.; Wang, G.; Chen, Q. H. Bioorg. Med. Chem. Lett. 2016, 26, 4241.

[40] Wang, Q.-A.; Wang, S.-C.; Li, Y.; Shan, Y. J. Hunan Univ. (Nat. Sci.) 2015, 42, 53 (in Chinese).

(汪秋安, 王盛淳, 李悦, 单杨, 湖南大学学报(自然科学版), $\mathbf{2 0 1 5}, 42,53$.)

[41] Zhang, J.; Fu, X. L.; Yang, N.; Wang, Q. A. Sci. World J. 2013, 2013, 649485 .

[42] Jian, J.; Fan, J.; Yang, H.; Lan, P.; Li, M.; Liu, P.; Gao, H.; Sun, P. J. Nat. Prod. 2018, 81, 371.

[43] Yamauchi, K.; Mitsunaga, T.; Batubara, I. Bioorg. Med. Chem. 2014, 22, 937.

[44] Liang, G.; Xu, B.; Wen, Z.; Hu, Z.; Yuan, J.; Chen, H.; Zhang, L. Heterocycles. 2016, 92, 1245.

[45] Xue, X.-N. Chem. Reag. 2018, 40, 465 (in Chinese). (薛向南, 化学试剂, 2018, 40, 465.)

[46] Liu, J. D; Chen, L.; Cai, S. C.; Wang, Q. A. Carbohydr. Res. 2012, $357,41$.
[47] Park, K. S.; Kim, H.; Mi K. K.; Kim, K.; Chong, Y. J. Korean Soc. Appl. Biol. Chem. 2015, 58, 317.

[48] Yang, W.; Sun, J.; Yang, Z.; Han, W.; Zhang, W. D., Yu B. Tetrahedron Lett. 2012, 43, 2773.

[49] Yang, W.; Sun J.; Lu, W.; Li, Y.; Shan, L.; Han, W.; Zhang, W.; Yu, B. J. Org. Chem. 2010, 75, 6879.

[50] Mei, Q.; Wang, C. Z.; Yuan, W.; Zhang, G. Beilstein J. Org. Chem. 2015, 11,1220 .

[51] Chen, J.; Huang, W.; Lian, G.; Lin, F. Carbohydr. Res. 2009, 344 2245.

[52] Koenigs, W., Knorr, E. Eur. J. Inorg. Chem. 2010, 34, 957.

[53] Zhao, J.; Zhang, Z.-P.; Chen, H.-S.; Zhang, X.-Q.; Chen, X.-H. Acta Pharm. Sin. 1998, 33, 22 (in Chinese). (赵晶, 张致平，陈鸿珊，张兴权，陈湘红，药学学报，1998，33， 22.)

[54] Vermes, B.; Farkas, L.; Nógrádi, M.; Wagner, H.; Dirscherl, R. Phytochemistry 1976, 15, 1320 .

[55] Farkas, L.; Nógrådi, M.; Vermes, B.; Wolfner, A.; Wagner, H.; Hörhammer, L.; Krämer, H. Eur. J. Inorg. Chem. 1969, 102, 2583.

[56] Mezey-Vandor, G.; Farkas, L.; Kanzel, I.; Ndgradi, M. Chem. Ber. 1980, $113,1945$.

[57] Docampo, M.; Olubu, A.; Wang, X. Q.; Pasinetti, G.; Dixon, R. A. J. Agric. Food Chem. 2017, 65, 7607.

[58] Huang, W. H.; Chien, P. Y.; Yang, C. H.; Lee, A. R. Chem. Pharm. Bull. 2003, 34, 339.

[59] Li, Y. F.; Yu, B.; Sun, J. S.; Wang, R. X. Tetrahedron Lett. 2015, 56, 3816.

[60] Demetzos, C.; Skaltsounis, A. L.; Tillequin, F.; Koch, M. Planta Med. 1990, 207, 131.

[61] Wang, Q.-A.; Wu, Z.; Liu, L.; Zou, L.-H.; Luo, M. Chin. J. Org. Chem. 2010, 30, 1682 (in Chinese). (汪秋安, 吴峥, 刘莉, 邹亮华, 罗茗, 有机化学, 2010, 30, 1682.)

[62] Cao, Z. L.; Qu, Y. Y.; Zhou, J. X.; Liu, W. W.; Yao, G. W. J. Carbohydr. Chem. 2015, 34, 28.

[63] Cao, Z. L.; Chen, J.; Zhu, D. D.; Yang, Z. N.; Teng, W. Q.; Liu, G. F.; Liu, B.; Tao, C. Z. J. Chem. Res. 2018, 42, 189.

[64] Nakagawa, A.; Tanaka, M.; Hanamura, S.; Takahashi, D.; Toshima, K. Angew. Chem., Int. Ed. 2015, 54, 10935.

[65] Du, Y.; Wei, G.; Lindhardt, R. J. Tetrahedron Lett. 2003, 44, 6887.

[66] Arai, M. A.; Yamaguchi, Y.; Ishibashi, M. Org. Biomol. Chem. 2017, 15, 5025 .

[67] Zou, L.; Zhang, Z.; Chen, X.; Chen, H.; Zhang, Y.; Li, J.; Liu, Y. Tetrahedron 2018, 74, 2376.

[68] Liao, J. X.; Fan, N. L.; Liu, H.; Tu, Y. H.; Sun, J. S. Org. Biomol. Chem. 2015, 14, 1221.

[69] Hu, Y.; Tu, Y. H.; Liu, D. Y.; Liao, J. X.; Sun, J. S. Org. Biomol. Chem. 2016, 14, 4842 .

[70] Yang, W.-Z.; Li, R.-Y.; Han, W.; Zhang, W.-D.; Sun, J.-S. Chin. J. Org. Chem. 2012, 32, 1067 (in Chinese).

(杨为准, 李荣耀, 韩伟, 张卫东, 孙建松, 有机化学, 2012, 32, 1067.)

[71] Carte, B. K.; Carr, S.; Debrosse, C.; Hemling, M. E.; Mackenzie, L.; Offen, P.; Berry, D. E. ChemInform 1991, 22, 1815.

[72] Lai, C. Y.; Tsai, A. C.; Chen, M. C.; Chang, L. H.; Sun, H. L.; Chang, Y. L.; Chen, C. C.; Teng, C. M.; Pan, S. L. Plos One 2012 7, e42192.

[73] Hsieh, I.; Chang, S. Y.; Teng, C. M.; Chen, C. C.; Yang, C. R. J. Biomed. Sci. 2011, 18, 28.

[74] Yao, C. H.; Tsai, C. H.; Lee, J. C. J. Nat. Prod. 2016, 79, 1719.

[75] Wang, Y.; Liu, M.; Liu, L.; Xia, J. H.; Du, Y. G.; Sun, J. S. J. Org. Chem. 2018, 83, 4111 .

[76] Yang, D.; Zhang, X.; Zhang, W.; Rengarajan, T. Drug Des., Dev. Ther. 2018, 12, 1303 .

[77] Ku, S. K.; Bae, J. S. Can. J. Physiol. Pharmacol. 2016, 94, 287.

[78] Shie, J. J.; Chen, C. A.; Lin, C. C.; Ku, A. F.; Cheng, T. J.; Fang, J. M.; Wong, C. H. Org. Biomol. Chem. 2010, 8, 4451.

[79] Sato, S.; Akiya, T.; Nishizawa, H.; Suzuki, T. Carbohydr. Res. 2006, $341,964$. 
[80] Ho, T. C.; Kamimura, H.; Ohmori, K.; Suzuki, K. Org. Lett. 2016, $18,4488$.

[81] Mao, D.-B.; Huang, S.-L.; Chen, Y.-S. China Surf. Deterg. Cosmet. 2007, 37, 321 (in Chinese). (毛多斌，黄顺利，陈永森，日用化学工业, 2007, 37, 321.)

[82] Hofer, B. Appl. Microbiol. Biotechnol. 2016, 100, 4269.

[83] Choung, W. J.; Hwang, S. H.; Ko, D. S.; Kim, S. B.; Kim, S. H.; Jeon. S. H.; Choi, H. D.; Lim, S. S.; Shim, J. H. J. Agric. Food Chem. 2017, 65, 2760.

[84] Kim, S. Y.; Lee, H. R.; Park, K. S.; Kim, B. G.; Ahn, J. H. Appl. Microbiol. Biotechnol. 2015, 99, 2233.

[85] Liang, C.; Zhang, Y.; Jia, Y.; Wang, W.; Li, Y.; Lu, S.; Jin, J. M.; Tang, S. Y. Sci Rep. 2016, 6, 21051.

[86] Pandey, R. P.; Parajuli, P.; Koirala, N.; Park, J. W.; Sohng, J. K. Appl. Environ. Microbiol. 2013, 79, 6833.

[87] Gurung, R. B.; Kim, E. H.; Oh, T. J.; Sohng, J. K. Mol. Cells 2013 , 36,355 .

[88] Liu, X. G.; Lin, C. L.; Ma, X. D.; Yan, Y.; Wang, J. Z.; Zeng, M. Front. Recent Dev. Plant Sci. 2018, 9, 166.

[89] Feng, J.; Zhang, P.; Cui, Y.; Li, K.; Qiao, X.; Zhang, Y. T.; Li, S. M.; Cox, R. J.; Wu, B.; Ye, M. Adv. Synth. Catal. 2017, 359, 955.

[90] Han, S. H.; Kim, B. G.; Yoon, J. A.; Chong, Y.; Ahn, J. H. Appl. Environ. Microbiol. 2014, 80, 2754.

[91] Pandey, R. P.; Parajuli, P.; Gurung, R. B.; Sohng, J. K. Enzyme Microb. Technol. 2016, 91, 26.

[92] Simkhada, D.; Lee, H. C.; Sohng, J. K. Biotechnol. Bioeng. 2010 , 107, 154.

[93] Kim, B. G.; Su, H. S.; Ahn, J. H. Appl. Microbiol. Biotechnol. 2012, 93, 2447.

[94] Brazierhicks, M.; Evans, K. M.; Gershater, M. C.; Puschmann, H.; Steel, P. G.; Edwards, R. J. Biol. Chem. 2009, 284, 17926.

[95] Du, Y.; Chu, H.; Chu, I. K.; Lo, C. Plant Physiol. 2010, 154, 324.

[96] Sasaki, N.; Nishizaki, Y.; Yamada, E.; Tatsuzawa, F.; Nakatsuka, T.;
Takahashi, H.; Nishihara, M. FEBS Lett. 2016, 589, 182.

[97] Shrestha, A.; Pandey, R. P.; Dhakal, D.; Parajuli, P.; Sohng, J. K. Appl. Microbiol. Biotechnol. 2018, 102, 1251.

[98] Vanegas, K. G.; Larsen, A. B.; Eichenberger, M.; Fischer, D.; Mortensen, U. H.; Naesby, M. Microb. Cell Fact. 2018, 17, 107.

[99] Du, Y.; Chu, H.; Wang, M.; Chu, I. K.; Lo, C. J. Exp. Bot. 2010, 61, 983.

[100] Morohashi, K.; Grotewold, E. Plant Cell. 2012, 24, 2745.

[101] Hirade, Y.; Kotoku, N.; Terasaka, K.; Saijo-Hamano, Y.; Fukumoto, A.; Mizukami, H. FEBS Lett. 2015, 589, 1778.

[102] Gutmann, A.; Nidetzky, B. Pure Appl. Chem. 2013, 85, 1865.

[103] Hao, B.; Caulfield, J. C.; Hamilton, M. L.; Pickett, J. A.; Midega, C. A.; Khan, Z. R.; Wang, J. R. Org. Biomol. Chem. 2015, 13 , 11663.

[104] Ito, T.; Fujimoto, S.; Suito, F.; Shimosaka, M.; Taguchi, G. Plant J. Cell Mol. Biol. 2017, 91, 187.

[105] Nagatomo, Y.; Usui, S.; Ito, T.; Kao, A.; Shimosaka, M.; Taguchi, G. Plant J. 2014, 80, 437.

[106] Mackenzie, L. F.; Wang, Q.; Warren, R. A. J.; Withers, S. G. J. Am. Chem. Soc. 1998, 120, 5583.

[107] Malet, C.; Planas, A. FEBS Lett. 1998, 440, 208.

[108] Moracci, M.; Trincone, A.; Perugino, G.; Ciaramella, M.; Rossi, M. Biochemistry 1998, 37, 17262.

[109] Hayes, M. R.; Pietruszka, J. Molecules 2017, 22, 1434.

[110] Kobayashi, S.; Shoda, S.; Uyama, H. Adv. Polym. Sci. 2012, 121, 217.

[111] Díez-Municio, M.; Kolida, S.; Herrero, M.; Rastall, R. A.; Moreno, F. J. J. Funct. Foods 2016, 20, 532.

[112] Ducros, V. M.; Tarling, C. A.; Zechel, D. L.; Brzozowski, A. M., Frandsen, T. P.; Ossowski, I. V.; Schülein, M.; Withers, S. G.; Davies, G. J. Chem. Biol. 2003, 10, 619.

[113] Yang, M.; Davies, G. J.; Davis, B. G. Angew. Chem. 2007, 46, 3885.

(Cheng, F.) 